\title{
Control data, Sankey diagrams, and exergy: assessing the resource efficiency of industrial plants
}

\author{
Ana Gonzalez Hernandez ${ }^{a}$, Richard C. Lupton ${ }^{a}$, Chris Williams ${ }^{b}$, \\ Jonathan M. Cullen ${ }^{a}$. \\ ${ }^{a}$ Dept. of Engineering, University of Cambridge, Trumpington St., Cambridge CB2 1PZ, UK \\ ${ }^{b}$ Tata Steel Port Talbot, Port Talbot SA13 2NG, UK
}




\begin{tabular}{llll}
\hline Nomenclature & & & \\
\hline Abbreviations & & & \\
& & ME & Material Efficiency \\
ADDS & Additions & MEFA & Material and Energy Flow Diagrams \\
AR & Argon & NIT & Nitrogen \\
BF & Blast Furnace & NG & Natural Gas \\
BOF & Basic Oxygen Furnace & OXY & Oxygen \\
BOS & Basic Oxygen Steelmaking & RE & Resource Efficiency \\
BOSG & Basic Oxygen Steelmaking Gas & RST & Rolled Steel \\
COG & Coke Oven Gas & SD & Sankey Diagram \\
CSLAG & Converter Slag & SM & Secondary Metallurgy \\
CST & Converted Steel & STD & Standard Deviation \\
DS & Desulphurised & TSLAG & Tapping Slag \\
DSHM & Desulphurised Hot Metal & TST & Tapped Steel \\
EE & Energy Efficiency & & \\
HM & Hot Metal & & \\
\hline
\end{tabular}

\section{Introduction: resource efficiency analysis at the plant-level}

Allwood et al. (2011) [1] showed that the reduction of material use in energy-intensive industries - measures under the rubric of material efficiency (ME) - is indispensable to achieve the agreed targets on $\mathrm{CO}_{2}$ emission reductions. In a series of studies, Cullen et al. [2,3], among others $[4,5]$, revealed that these industries are currently wasteful; around half of all steel and aluminium produced is either scrapped in production, or used unnecessarily in over-specified products. Not all of these losses are recoverable, but there are significant practically achievable solutions to reduce existing material losses in energy-intensive industries [6-9]. In fact, in these industries, energy savings from ME measures have the potential to deliver larger savings than energy efficiency (EE) [5]. To realise these opportunities, however, individual industrial firms must identify and prioritise ME interventions at actionable time-frames and scopes that is, within boundaries directly controlled by a given firm. For this to happen, a detailed awareness of resources flows is needed.

For many decades, academics have been interested in tracking the resource use of industrial processes; Table 1 shows a selection of relevant studies across a range of academic fields. These are classified using five criteria, namely whether they: (1) are representative of real plant operations across time (denoted as 'type of data used'); (2) analyse resource use at actionable time frames and (3) scopes (temporal and spatial granularities); (4) cover both energy and materials jointly; and (5) visualise resource flows using Sankey diagrams (SDs).

Because improvements in industrial resource use have traditionally focused on increasing EE, most energy studies neglect ME measures, i.e. the first seventeen studies in Table 1. The few studies that analyse the energy-saving potential of ME have focused on either measuring material yields (in mass) $[38,39]$ or on quantifying cumulative savings, e.g. as embodied energy or emissions $[6,40]$. Conventional energy studies and recent analyses of ME fail to quantify how efficiently industry uses both energy and materials (the combination of which is henceforth denoted as resource efficiency (RE)). In doing so, these studies overlook the 


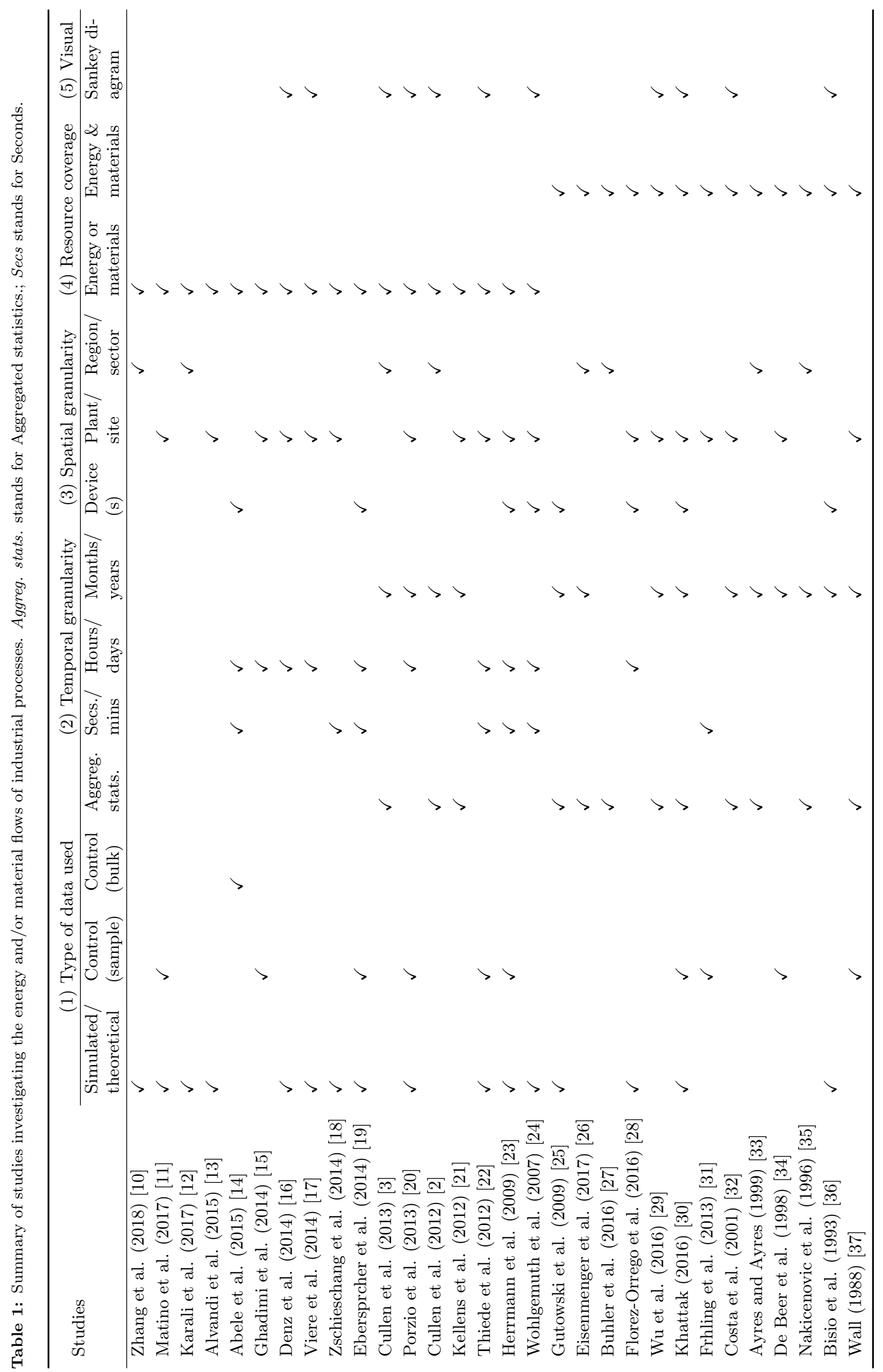


fact that in complex industrial systems, energy and material flows are interrelated and often interchangeable.

Without an integrated resource efficiency metric, analysing energy and materials under a single framework becomes challenging. To resolve this, academics developed the concept of exergy. Many studies have confirmed the benefits in using exergy as a proxy to quantify the $\mathrm{RE}$ with which energy-intensive industries produce bulk materials [41-43], namely that this can: capture upgrades in the quality of materials and the dissipation of high-value fuels into low-value heat; reflect resource quality and give insight into which resource streams are worth recovering - those with high exergy content; capture the benefits associated with recovering material by-products, e.g. slag, which cannot be done using energy-based metrics; provide a dimensionless measure that can be used to compare efficiencies across sectors.

Exergy analyses performed at system levels relevant to individual industry firms, where day-to-day operational decisions are made, are often based on simulation software, such as Umberto $\AA$ or Anylogic $\AA$, or on aggregated data collected in annual reports. Examples of analyses using annual data include work by Costa et al. (2001) [32] and Wu et al. (2016) [29], where the exergy efficiency of an indicative steel plant and a Chinese steel network are respectively investigated. Analysis based on modelled or theoretical data include studies by Szargut et al. [42] (for metallurgical and chemical industries), de Beer et al. (1998) [34] (for a reference steel plant) and Florez-Orrego et al. (2016) [28] (for an ammonia simulation). Only occassionally, is control data used in to validate resource assessment simulations. For example, Khattak (2016) [30] combines control data samples, experiments and models to analyse the resource use of a sugar factory and a manufacturing plant.

Analyses on resource use often capitalise on the power of data visualisations to shed light onto the scale and structure of a system's underlying flows. Today, Sankey diagrams are one of the most widely used tools to do this. Table 1 indicates which of the reviewed studies employ these - Schmidt (2008) [44] and Soundararajan et al. (2014) [45] provide more detailed reviews of applications of SDs in industry. A perusal of the studies in Table 1 reveals that among the few exergy studies conducted at the plant-level, Sankey diagrams have been used to portray simulation or theoretical data.

With the soaring capabilities of digital devices, the decline in the price of electronics and the improvements in data analytic methods, there is an opportunity to automatically use available control data to analyse resource efficiency and to visualise resource use at actionable scopes for plant managers. This could help reduce the amount of time, expertise and money needed to conduct energy and material audits [46] - currently viewed as problematic by energy-intensive industries in Europe. Yet, none of the exergy studies in Table 1 exploit this potential, and a holistic picture of energy and materials that is representative of real-time operations is therefore yet to be provided. 


\section{$1.1 \quad$ Research novelty}

Detailed information on resource flows and efficiency at actionable time-scales and scopes, i.e. close to real-time, is key to encourage industry to reduce resource use. It is therefore crucial that firms have the appropriate instruments to jointly analyse and visualise energy and materials; these must be complex enough to capture the nuisances of real operations yet simple enough to be easily communicated to decision-makers. This study aims to provide such a tool by answering the following question:

Can available control data for energy and material flows be used to provide a meaningful analysis of resource use and resource efficiency improvements during real plant operations?

We propose a method that helps plant managers make on-site decisions on resource efficiency interventions, and which capitalises on three tools: (1) the well-established exergy approach to combine the analysis of energy and materials; (2) the use of control data collected on a real-time basis through plant meters; (3) Sankey diagrams as a means to transparently depict the combined flows of energy and materials. The analysis is explored using the case study of a Tata Steel basic oxygen steelmaking (BOS) plant.

The rest of this paper is structured as follows. Section 2 details the method used to process control data into a holistic resource efficiency analysis. Section 3 describes the resource use and efficiency of the BOS plant and its internal processes, and compares the exergy-based metric to conventional energy intensity indicators. Section 4 discusses these results.

\section{Methodology}

The method is described in four steps: the outline of the system structure and raw data (Section 2.1); the balancing of resources (Section 2.2); the conversion of resource flows into exergy and the calculation of resource efficiencies (Section 2.3); the visualisation of resource flows (Section 2.4). From this, improvement options are evaluated (Section 2.5).

\subsection{Describing the system boundaries and raw data inputs}

BOS is an oxidation process that reduces the carbon content from $4.5 \mathrm{wt} . \%$ in iron to 0.05 to 0.25 wt. $\%$ in steel, while producing by-products such $\mathrm{CO}, \mathrm{CO}_{2}, \mathrm{SiO}_{2}, \mathrm{MnO}$ and iron oxides (released as product gases or trapped in slag). Four key processes are studied (portrayed in Figure 1): (1) the desulphurisation of the hot metal, where lime and magnesium are added to reduce the metal's sulphur content; (2) the oxidation process in the converter; (3) the tapping of the steel from the converter, where additions are sometimes added; and (4) the refining of the steel - denoted as secondary metallurgy (SM), where the steel grade is defined through additions of ferro-alloys, carbon and top slags either in degassers or argon stirrers.

Information on the structure of the resource flows can, in theory, be obtained from process flow diagrams. Yet, in practice, diagrams with the right level of information are rarely 


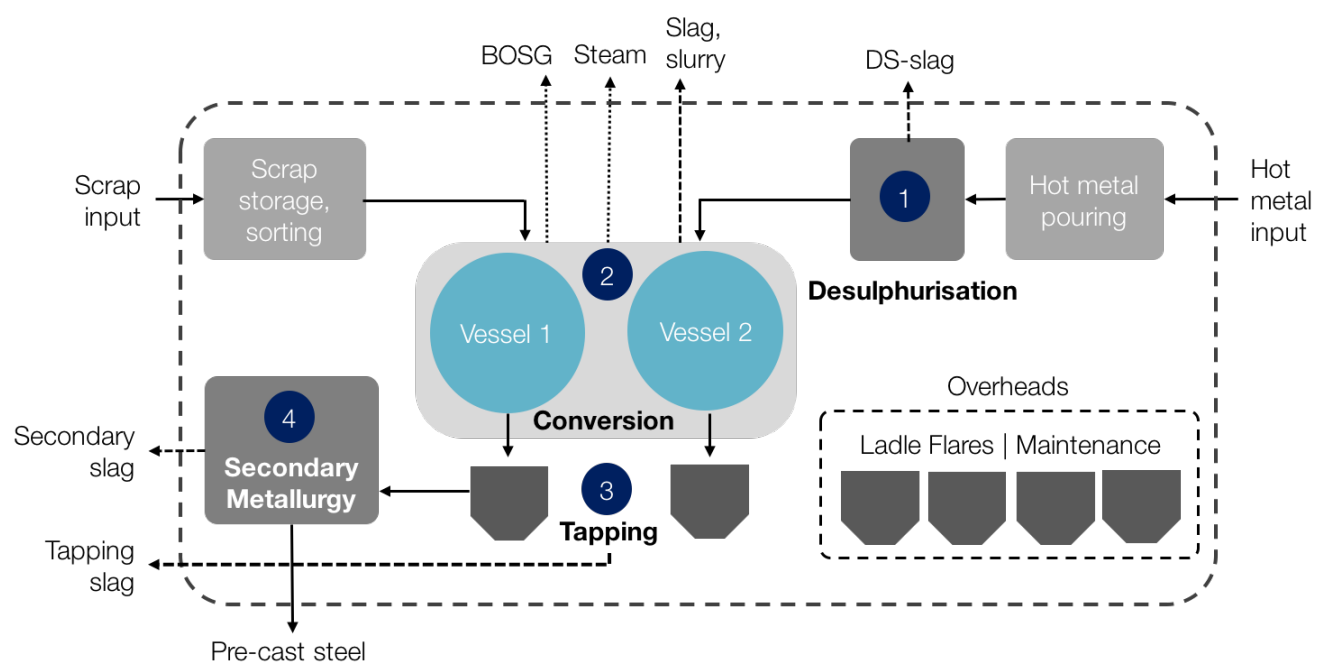

Figure 1: BOS plant process structure and system boundaries

available, and it is necessary to rely on conversations with on-site experts to define the wire structure underpinning the plant's internal resource flows.

Figure 2 portrays the levels at which the data are obtained. Six types of control data are collected: mass flows, energy, physical properties (e.g. temperature and pressure), composition, time-stamps and batch-numbers. Ideally, the control data for every resource flow is available at the highest level of granularity, that is, for every batch. In practice, there are multiple data sources, each of which is metered at different time scales and at different system levels.

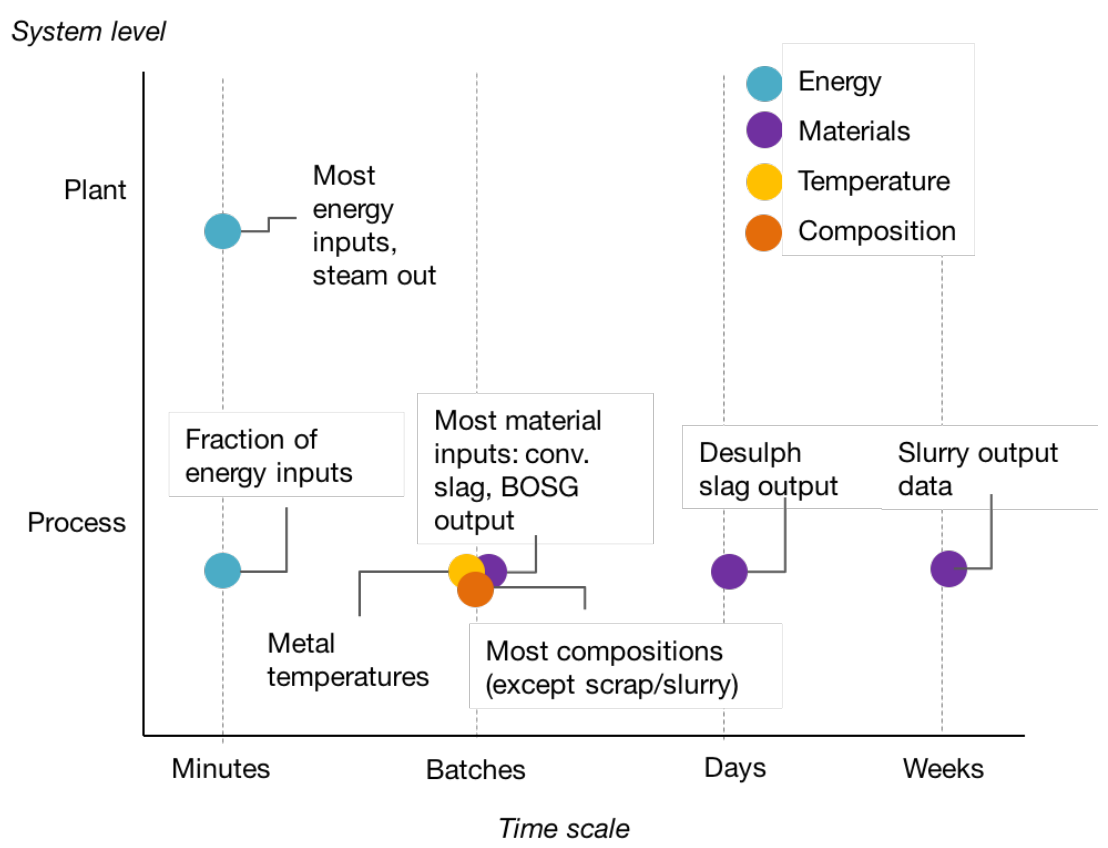

Figure 2: Data availability described in terms of time scales and system levels. An example depicting the discrepancy in sampling rates is the composition data, i.e. an average scrap composition is available, whereas converter slag, hot metal and steel compositions are known for every batch.

Energy data, both at a plant- and process-level, are metered continuously and is available 
on a per minute basis. Plant-level energy meters measure: the input of natural gas (NG), electricity, nitrogen, oxygen and coke oven gas (COG), as well as the generation of BOS gas (BOSG) and steam in the converter. Electricity and nitrogen are fed to all four processes, whereas oxygen is input to the converter process only, and the gas inputs are only used for the pre-heating of ladles (e.g. overheads).

All other material inputs are measured discretely, at the point when the material is charged to the process. Unlike with the energy data, the batch, time and location stamps allow for materials to be directly attributed to specific processes and batches. The main material flows are the hot metal input and intermediate flows, and the refined steel output. Other minor material inputs include: fluxes (e.g. magnesium, dolomite or lime); additions, such as ore or ferro-alloys; and steel scrap. The remaining material flows primarily include by-products such as slags and slurry.

Figure 2 portrays that the availability and format of the composition and physical data is more inconsistent. Most composition data is available on a batch-level; i.e. for the hot metal, steel, BOS gas, and converter slag. For the rest of the materials, including scrap, fluxes, additions, other slags and slurry, average composition data is used. Details on how these are computed are included in Tables A.3, A.4 and A.5 in the Supplementary Material. Data on the physical properties of materials is only available for: every batch of the metal flows (e.g. hot metal and steel) and every minute of the steam outputs. Information on the start and end times of individual processes is provided in a control log.

\subsection{Outlining the system structure of material and energy flows}

The exercise of tracing resource flows is denoted as material and energy flow analysis (MEFA). The main feature of MEFA models is that they are governed by the principle of material and energy conservation. Assuming that the storage of mass is negligible (in this case this is small compared with the steel flows) this balancing principle can be expressed mathematically as shown in Equation 2.1. Here, $x$ is any substance - such as energy, mass, or exergy - that is conserved. $k_{I}$ and $k_{O}$ are the number of flows that are input and output respectively.

$$
\sum_{k_{I}} x_{\text {input }}=\sum_{k_{O}} x_{\text {output }}
$$

Following this principle, resource flows need to balance at every point in time. At the highest resolution, each process is analysed in batches; at the lowest resolution, the entire plant is analysed across 24 hours, starting at midnight. We begin by describing the modelling exercise at the batch-level, and later explain how this is aggregated to days.

Figure 3 portrays the structure of the resource flows, each of which is colour-coded according to the type of data input. Calculations relevant to all processes are described first. Aspects specific to individual processes are subsequently described by navigating this figure. The flow 
numbers in Figure 3 are used to help the reader identify these more easily.

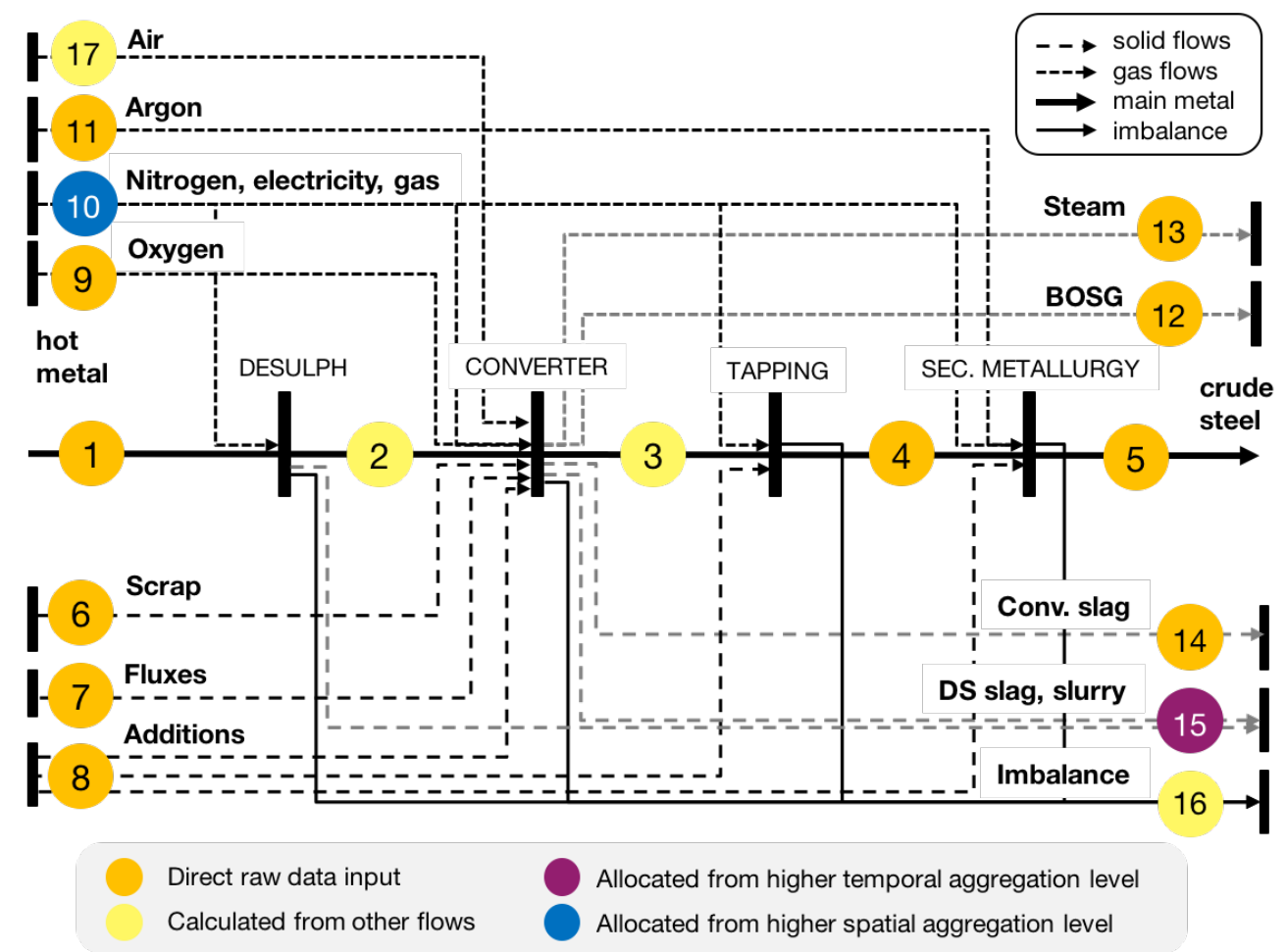

Figure 3: Resource flow wire structure. Colour is used to distinguish between the various ways in which the mass values were obtained for the different flows.

\subsubsection{General assumptions}

Three main assumptions are made that apply to all processes:

- The nitrogen and argon input into the processes is assumed to be vented.

- Energy inputs that cannot be allocated to individual processes are assumed to be consumed as overheads.

- The difference between inputs and outputs is considered an imbalance. If positive, this is assumed to consist of process irreversibilities. If negative, this is assumed to capture errors in the chemical exergy of scrap.

To provide a meaningful picture of the plant's internal flows, energy inputs need to be allocated to each process. The process-level energy inputs - NG, COG, electricity and nitrogen - are estimated using ordinary least-squares regression, assuming a process consumption profile linearly varying between the start, middle and end of the process, based on timings from control log files. The regression explains about $10 \%$ of the electricity and nitrogen use; the remainder is classified as daily overheads.

Unlike energy inputs, which are metered every minute, some materials are measured at high temporal aggregation levels. For example, the slurry and the DS slag are measured weekly and hourly respectively. These flows have to be allocated down temporally, and in the absence of better information, we assume they are distributed linearly across batches and days. 


\subsubsection{Process-level calculations}

During desulphurisation (desulph), the sulphur content in the hot metal (HM) is reduced through the input of lime and magnesium $(\mathrm{Mg})$. HM is input (1) alongside two energy inputs (10) - electricity and nitrogen (NIT), both of which are allocated from plant-level metering. Outputs include desulphurised hot metal (DSHM) and slag (15). This slag is skimmed from the metal before this is poured into the converter. In mass units, this is described by:

$$
m_{M G}+m_{\text {lime }}+m_{H M}+m_{N I T}=m_{D S H M}+m_{\text {slag }}+m_{N I T}
$$

Secondary Metallurgy (SM) is considered next because SM data is used to back-calculate the tapping steel (TST) input and converter output flows (3). Here, steel is refined (4) before it is cast. Steel can be refined using two types of processes, namely argon stirring or vacuum degassing. These involve different types of processes, but for the modelling exercise, the relevant difference is that argon stirrers consume argon (AR), whereas the degassers use steam. Equation 2.3 describes the flows for the two processes combined, where RST stands for refined steel.

$$
\begin{array}{r}
m_{A D D S}+m_{T S T}+m_{A R}+m_{T S L A G}+m_{N I T}+m_{\text {steam }} \\
=m_{R S T}+m_{S S L A G}+m_{N I T}
\end{array}
$$

All data inputs $(8,10,11)$ are known except for $(3)$ and the secondary slag (SSLAG). The former is calculated by assuming this to be the same as (5), i.e. that the metal yield is equal to $100 \%$. The latter is calculated as the difference between the inputs and the outputs.

The converter has multiple material inputs - including scrap (6), fluxes (7), additions or ADDS (8), and DSHM (2) - and material outputs, namely converted steel (CST), converter slag (CSLAG) and slurry $(14,15)$. It consumes NIT, electricity (10), oxygen (9) denoted as OXY, and produces BOSG (12) and steam (13). Air (17), which is sucked into the BOSG, is calculated and included in the mass balance. Equation 2.4 summarises these flows.

$$
\begin{array}{r}
m_{A D D S}+m_{\text {fluxes }}+m_{D S H M}+m_{\text {scrap }}+m_{O X Y}+m_{N I T}+m_{\text {air }}= \\
m_{C S T}+m_{C S L A G}+m_{\text {slurry }}+m_{\text {steam }}+m_{B O S G}+m_{N I T}
\end{array}
$$

During tapping, the steel from the converter is poured into a ladle. In doing so, some CSLAG is carried over (15). During this process, NIT and electricity are consumed (10) and additions are often input (8). The resource flows are summarised in Equation 2.5.

$$
m_{A D D S}+m_{C S T}+m_{C S L A G}+m_{N I T}=m_{T S T}+m_{T S L A G}+m_{N I T}
$$

The tapped steel (TST) is assumed to be equal to the input to SM. The tapping slag (TSLAG) 
is calculated as the difference between refined (RST) and converted steel (CST).

\subsubsection{Data filtering}

Processing large volumes of unstructured data requires data cleaning. Raw data can be logged into the control system in two ways: automatically or manually. Both can cause errors in the data, either in the form of wrong or missing values. For example, the operator may input the wrong value for a given flow in a given batch. Similarly, for a given flow in a given batch, the control system may fail to log a flow value at all. These missing or conflicting values in the raw data must be resolved before the model described above can be applied.

All of the data inputs can contain errors, including the time-stamps and batch numbers. Different mechanisms are devised to filter the missing or conflicting data points for different types of data. Table A.1 in the Appendix depicts the decisions made to fix these errors.

\subsection{Measuring resource use and resource efficiency in exergy units}

In metallurgical processes, the physical $\left(b_{p h}\right)$ and chemical $\left(b_{c h}\right)$ are the most relevant components of the exergy. Therefore, this analysis considers the chemical exergy (capturing differences in composition and concentration) and the physical exergy (capturing differences in pressure and temperature) of energy and materials.

\subsubsection{Calculating chemical exergies}

The composition of a material is the mainstay of its chemical exergy. For materials with composition data available, this is calculated from first principles. Equation 2.6 from Szargut et al. (2005) [47] can be used to determine the chemical exergy of specific materials:

$$
b_{c h}^{m a t}=\sum_{i} n_{i} b_{c h, i}+R T_{o} \sum_{i} n_{i} \ln \left(a_{i}\right)
$$

where $b_{c h}^{m a t}$ refers to the chemical exergy of the component, $n_{i}$ represents the number of moles in the ith component, $a_{i}$ stands for the component's activity, $R$ is the gas constant and $T_{o}$ is the temperature of the reference environment. Reuter et al. (2005) [48] argue that the $b_{c h}^{\text {mat }}$ of metal alloys can be calculated using Equation 2.6 by approximating $a_{i}$ with the mole fraction $\left(n_{i}\right)$. Equation 2.6 is used to calculate the $B_{c h}$ of the input hot metal, the outputs of BOSG, converter slag and steel.

For materials with no composition data, averaged values are used. These are obtained from tabulated results usually assuming the most commonly found compositions [33, 49, 50]. Tabulated values of specific chemical exergies are used for most of the additions, fluxes and scrap inputs, input gases (i.e. nitrogen, argon, oxygen, air), all other slags and slurry. Tables A.3, A.4 and A.5 in the Supplementary Material give detailed explanations. 
For fuels, for which no composition is available, calculating $B_{c h}$ is simpler than for materials. The inherent similarities between fuel heating values and their chemical exergies (within 10\%), make it possible to directly convert from one to the other. Academics, such as Nakicenovic et al. (1996) [35], have defined conversion factors $(f)$ for the main energy carriers, including coal, NG or electricity. Nakicenovic's conversion factors are used for NG and electricity.

\subsubsection{Calculating physical exergies}

There are two ways of calculating the physical exergy of resources; directly or indirectly. In both cases, it is important to define a reference state as this affects the work that can be extracted from a process ${ }^{1}$. The direct method is based on enthalpies $(\mathrm{H})$ and entropies (S), as per Equation 2.7, where $\mathrm{H}_{0}$ and $\mathrm{S}_{0}$ are those at ambient conditions. The IAPWS Python package is used to calculate $\mathrm{H}$ and $\mathrm{S}$ for the steam flows in each batch; these are calculated using inputs of minute-level metered data on steam temperatures and pressures [51].

$$
b_{\mathrm{ph}}^{\text {direct }}=\left(H-H_{0}\right)-T_{0}\left(S-S_{0}\right)
$$

The indirect method consists of expressions that approximate the enthalpies and entropies of the substances. Different equations are used depending on the conditions and assumptions made. For example, assuming a constant specific heat $\left(C_{p}\right)$, Querol et al. (2013) [52] use Equation 2.8. This is used to calculate the $b_{p h}$ of the metal flows.

$$
b_{\mathrm{ph}}^{\text {indirect }}=C_{p}\left(T-T_{0}\right)-T_{0} C_{p} \ln \left(\frac{T}{T_{0}}\right)+T_{0} R \ln \left(\frac{P}{P_{0}}\right)
$$

\subsubsection{Calculating exergy losses}

Unlike mass and energy, exergy is not conserved. Instead, this is destroyed whenever a real (rather than ideal) process takes place [53]. This destruction is often referred to as irreversibilities, which result primarily from heat transfers occurring across finite temperature differences, combustion and chemical reactions, and the expansion and compression of fluids. Combinations of these phenomena are present in all devices.

Representing the exergy irreversibilities as output flows in the Sankey diagram, despite not physically being there, allows the exergy flows to be comply with the format required for conventional MEFAs. Irreversibilities are determined by calculating the difference between the total exergy inputs and the total exergy outputs.

\footnotetext{
${ }^{1}$ The reference temperature and pressure used are $\mathrm{T}_{0}=25^{\circ} \mathrm{C}$ and $\mathrm{P}_{0}=101.325 \mathrm{kPa}$ respectively.
} 


\subsubsection{Defining resource efficiency}

Exergy efficiency is commonly described as the ratio of useful (or desired) exergy output to the total exergy inputs as in Equation $2.9[41,42,54]$. The numerator and denominator are both measured in joules, and the useful exergy output can never exceed the exergy input, so these always range between 0 and 1. Many definitions of efficiency are possible as a judgment must be made for each process in order to distinguish between products (useful outputs), by-products and wastes. The exact nature of this classification is arbitrary, may change over time and depends on the boundaries considered.

$$
R E=\frac{\sum\left(B_{c h}+B_{p h}\right)_{\text {useful }}}{\sum\left(B_{c h}+B_{p h}\right)_{\text {total }}}
$$

In this study, the term useful refers to resources that are fed into other processes. For example, the collected BOSG is considered useful, but that flared is considered waste. Wastes include material losses, such as unused by-products (e.g. stockpiled slag or sludge) and air emissions (mainly $\mathrm{CO}_{2}$ ). Table 2 depicts the specific $\mathrm{RE}$ definitions adopted for each process and for the BOS plant as a whole. It becomes useful to distinguish between wastes and irreversibilities described in Section 2.3.3 when defining the potential for improvements: wastes can be reduced or recovered, while irreversibilities are often unavoidable.

Table 2: RE definitions of the four processes and the BOS plant; nit. stands for nitrogen, and elec. for electricity

\begin{tabular}{|c|c|c|c|c|}
\hline \multirow{2}{*}{ Process } & \multicolumn{2}{|c|}{ Useful outputs } & \multicolumn{2}{|l|}{ Total inputs } \\
\hline & $B_{c h}^{u s e f u l}$ & $B_{p h}^{u s e f u l}$ & $B_{c h}^{\text {total }}$ & $B_{p h}^{\text {total }}$ \\
\hline Desulph & $\begin{array}{l}\text { Desulphurised } \\
\text { hot metal }\end{array}$ & $\begin{array}{l}\text { Desulphurised } \\
\text { hot metal }\end{array}$ & $\begin{array}{l}\text { Hot metal, lime, magnesium, nit., } \\
\text { elec. }\end{array}$ & Hot metal \\
\hline Converter & $\begin{array}{l}\text { Converted steel, } \\
\text { recovered BOSG }\end{array}$ & $\begin{array}{l}\text { Converted } \\
\text { steel, steam }\end{array}$ & $\begin{array}{l}\text { Desulphurised hot metal, scrap, } \\
\text { fluxes, additions, nit., elec. }\end{array}$ & $\begin{array}{l}\text { Desulphurised } \\
\text { steel }\end{array}$ \\
\hline Tapping & Tapped steel & Tapped steel & $\begin{array}{l}\text { Converted steel, additions, nit., } \\
\text { elec. }\end{array}$ & $\begin{array}{l}\text { Converted } \\
\text { steel }\end{array}$ \\
\hline $\begin{array}{l}\text { Secondary } \\
\text { Metallurgy }\end{array}$ & Refined steel & Refined steel & $\begin{array}{l}\text { Tapped steel, additions, nit., elec., } \\
\text { steam, argon }\end{array}$ & Tapped steel \\
\hline Plant & $\begin{array}{l}\text { Refined steel, re- } \\
\text { covered BOSG }\end{array}$ & $\begin{array}{l}\text { Refined steel, } \\
\text { steam }\end{array}$ & $\begin{array}{l}\text { Scrap, lime, magnesium, fluxes, ad- } \\
\text { ditions, nit., elec., NG, COG, argon }\end{array}$ & Hot metal \\
\hline
\end{tabular}

The energy intensity (EI) of the BOS plant is computed to allow comparisons with the exergybased resource efficiency. To protect the company's proprietary data, the EI is normalised to its absolute maximum ( $\left.E I_{\text {norm }}\right)$, as expressed in Equation 2.10 .

$$
E I_{\text {norm }}=\left(\frac{E_{\text {inputs }}-E_{\text {by-prod }}}{M_{\text {prod }}}\right) E I_{\text {max }}^{-1}
$$




\subsection{Visualising the resource data}

Sankey diagrams describe a system using arrows of thickness proportional to their flow magnitude and present a useful snapshot of a system's behaviour at a given time. In this study, SDs are used to visualise resource flows (in gigajoules of exergy). Resource flows are depicted for several system levels and time scales, namely batch- and daily-level diagrams for processes and the entire plant. In these diagrams, the dimension of colour is used to distinguish between different types of materials. Individual resource flows that are too small to show up on the SD are grouped as outlined in Section A.2 of the Appendix.

An open-source, Python-based tool developed by Lupton and Allwood (2017) [55,56] is used to construct these diagrams. This tool allows us to animate individual daily and batch-level Sankey diagrams across the 29 days and 900 batches respectively. A snippet of these is supplied as an online video. The range of REs across batches and days is depicted in the form of histograms. These are plotted in Python using the Matplotlib [57].

\subsection{Calculating the resource use improvements}

To exemplify how this analysis can facilitate the comparison between energy and material efficiency options, we calculate the improvements available from the following options:

- From within material efficiency (ME) options:

- The recovery of converter slag for further use in other processes across batches

- The recovery of other slag for further use in other processes across batches

- The recovery of slurry for further use in other processes across batches

- From within the energy efficiency (EE) options:

- Increasing the amount of BOSG recovered across batches

- Decreasing the amount of overheads (gas, electricity) consumed daily

Three aspects need to be considered when quantifying the size of these improvements. First, the current resource efficiency of the process. Second, the scale of the flows. Third, the limit for improvement available. The value of this limit depends on the criteria used to define it, i.e. whether it is based on economic, technical or theoretical considerations. In this analysis, only technical engineering limits are considered. Table 3 summarises these for each of the measures listed above, including the reasoning behind the choice of these.

By measuring the resource flows in units of exergy it is now possible to compare the improvements available form both EE and ME. Bakshi et al. (2011) [59] explain that when interpreting the meaning of these improvements, it is useful to consider the view developed in the resource accounting literature: the chemical exergy of the material by-products (the intrinsic) expresses the theoretical amount that can be saved if these materials are input as 
Table 3: Limits on improvement measures. Worldsteel average sourced from [58]; tst stands for a tonne of steel.

\begin{tabular}{lll}
\hline Improvement option & Limit & Reasoning \\
\hline Converter slag recovery & $90 \%$ of mass & $10 \%$ higher than worldsteel average \\
Other slag recovery & $90 \%$ of mass & As for converter slag \\
Slurry recovery & $90 \%$ of mass & Assumed limits equal to slag \\
BOSG recovery & $85 \%$ of vol. produced & $\sim 5 \%$ above maximum observed \\
Reduction in overheads & To 0.09 GJ/tst & $10 \%$ below minimum observed \\
\hline
\end{tabular}

raw materials elsewhere. This intrinsic exergy is independent of the process that produced it in the first place, and does not include that embodied (i.e. the process losses).

\section{$3 \quad$ Results}

The method described above is applied to the case study of a Tata Steel Basic Oxygen Steelmaking plant. At plant-level, we analyse the resource-use variations across days, whereas at process-level these are investigated across batches. Section 3.1 describes the resource flows and efficiencies, whereas Section 3.2 summarises the resource-use improvements available. RE values are then compared to conventional energy intensity metrics (Section 3.3).

\subsection{Resource flows and efficiencies}

Figure 4 shows the resource flows and efficiency for the BOS plant measured in units of exergy. The Sankey diagram (Figure 4a) portrays the flows for a specific day, and the RE distribution across the 29 days is highlighted in Figure 4b. Both diagrams reveal several insights into the operation of the BOS plant. The chemical exergy of the material flows dominates that of the energy flows, with the hot metal and scrap inputs, and the steel output, being the three largest flows. Figure 4a portrays two main energy by-products: steam $(\sim 2 \%$ of total exergy input), which is currently recovered in a super-heater and exported to other on-site plants; and BOSG ( 10\% of total input), which is divided into two, that currently flared (light blue) and that already recovered for further use on-site (dark blue).

As the chemical exergy of this gas is significant, every effort should be made to recover its chemical content. Slag (2-4\% of total input) and slurry ( $\sim 1 \%$ of total input) are the two material by-products. Process irreversibilities (in the imbalance term) represent about 2-5\% of the total exergy input. These losses are largely unavoidable, although a fraction of them may be reduced by further optimising process conditions.

The RE of the BOS plant (Figure 4) has a skewed bi-modal distribution, ranging from 82.5 to $88.4 \%$. Across the 29-day period, the BOS plant has a mean RE of $87.9 \%$, with an absolute standard deviation (STD) of $2.5 \%$. The bi-modal shape arises mainly due to the differences in the amount of BOSG collected. Although the minimum RE in Figure 4 appears to be an outlier, the short time period studied makes it difficult to judge these. The differences in the 


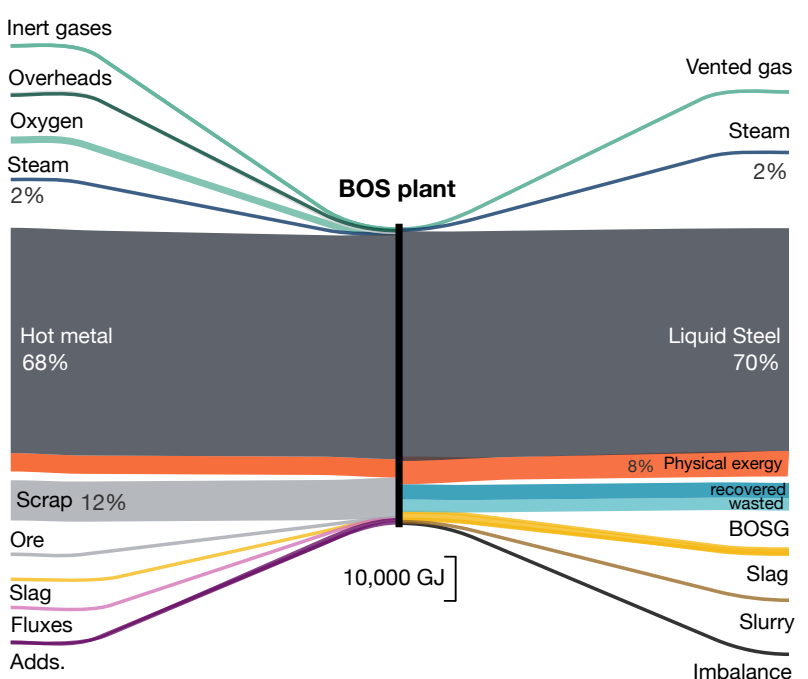

(a)

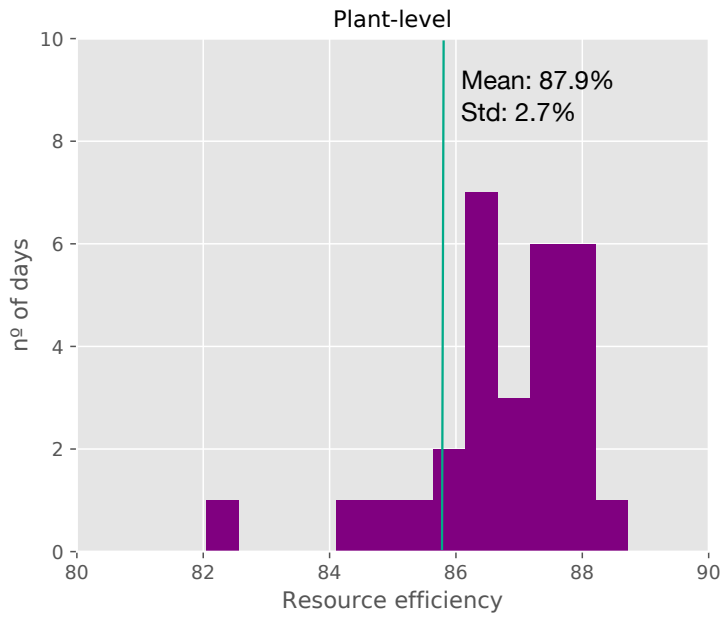

(b)

Figure 4: (a) SD of plant-level resource flows for a given day, measured in units of exergy; (b) Daily-level REs for the entire plant across the 29-day period.

daily steel-to-slag and steel-to-slurry ratios have no influence over this RE as they were not recovered for further use during this time period. The heterogeneity results from variations in: the difference in grades produced, the scrap-to-iron inputs, waiting and duration times between and of processes, and the consumption of overheads (e.g. NG or electricity).

The histogram in Figure A.1 in the Appendix shows the RE variations across batches, where the RE ranges from $75 \%$ to $96 \%$, with a bi-modal shape. Comparing Figure A.1 and Figure $4 \mathrm{~b}$ it is possible to deduce batch-level variations appear to be averaged out when aggregated to the daily scale. The heterogeneity observed both daily and across batches, shows there is still potential for improvement. To investigate this further, the resource flows and efficiencies of the processes are analysed.

Figure 5a shows a more detailed view of the BOS plant, disaggregated into four processes. The SD depicts the resource flows for a specific batch, and the histograms portray the RE variation for each process across the 29 days. Disaggregating the plant-level RE shows its variance comes from the converter (2), as the majority of fuels, by-products, and irreversibilities arise here. Harnessing the physical exergy of the steel (6-7\% of total inputs) has the potential of saving energy, particularly when moving across plants, e.g. between BOS and rolling.

Figure $5 \mathrm{~b}$ shows that across the 29 days, the converter is the least resource efficient process. The converter has a mean $\mathrm{RE}$ of $91.6 \%$, and is the most variable process, with an absolute STD of 2.5\%. In contrast, the desulph, tapping and SM processes have mean REs of $98.9 \%$, $98.5 \%$ and $98.2 \%$ respectively, with small STDs $(0.3 \%, 0.7 \%$ and $0.4 \%)$. From this variability, the resource-use improvement potential is quantified. 


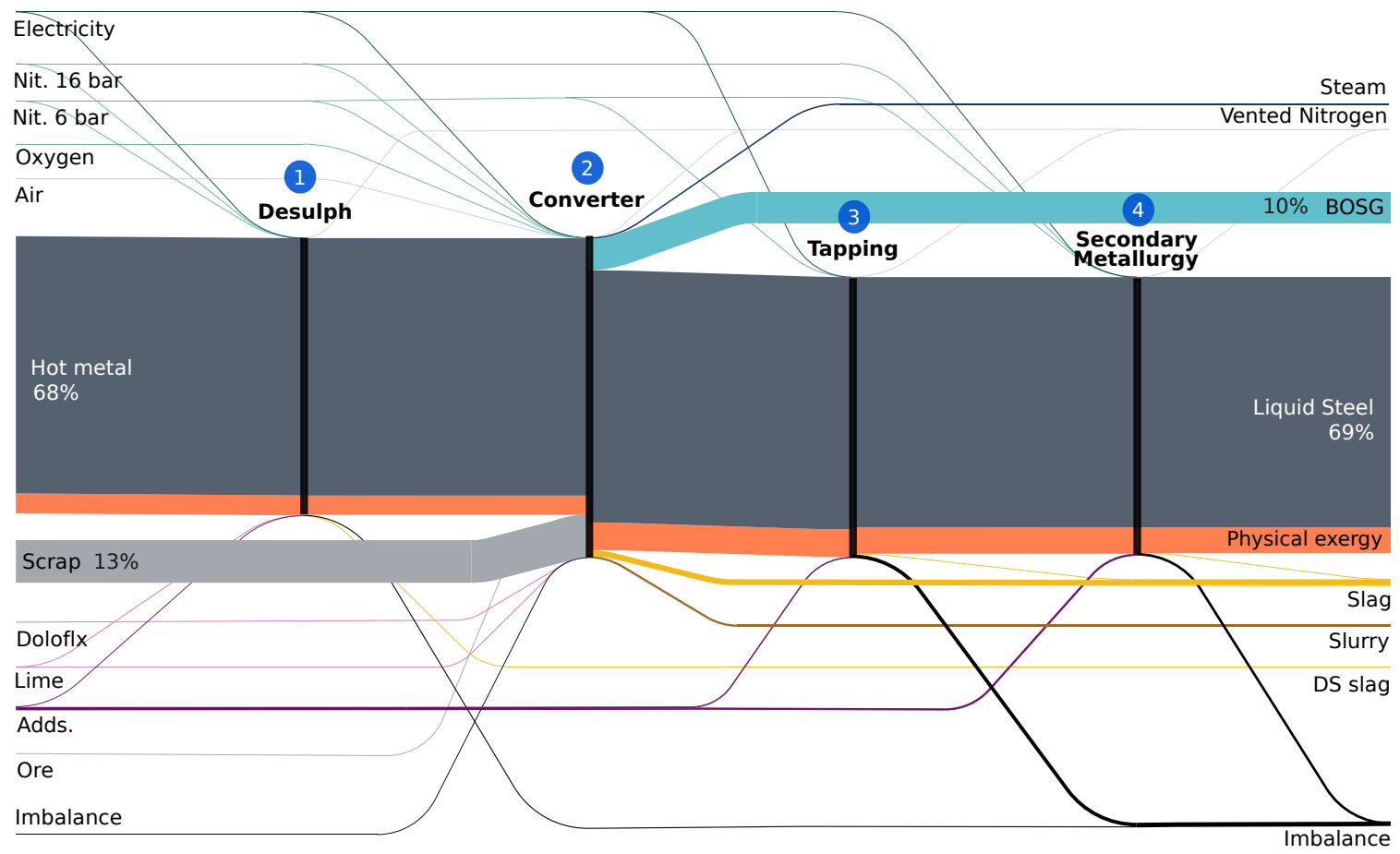

(a)
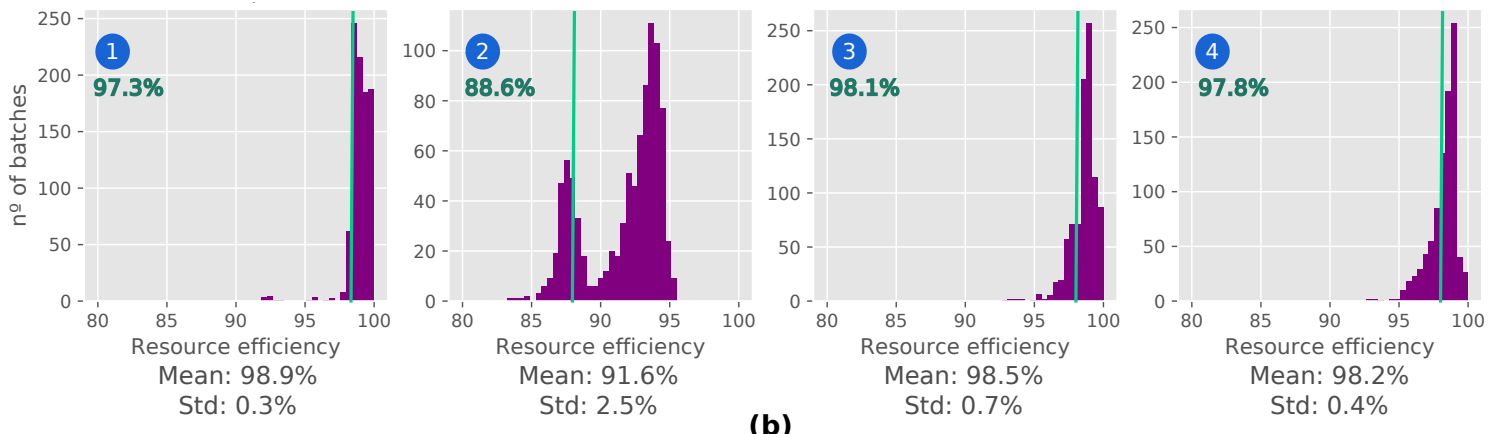

Figure 5: (a) SD for a specific batch (measured in exergy); (b) Histograms of the RE variations across batches for each of the four processes. Values in green reflect the REs of the batch in (a). The means and standard deviations

(Std) across the 29 days are depicted below the histograms.

\subsection{Resource use improvements}

Figure 6a illustrates the current RE variations of the processes across time, and the resource use improvements available from energy-related (Figure 6b) and material-related options (Figure 6c). For confidentiality reasons, the resource use improvements are measured in relative terms, i.e. as a percentage of the total daily exergy input.

The implementation of the measures outlined in Section 2.5 results in cumulative resource-use improvements equivalent to $7.1 \%$ of the resource inputs (in exergy) across the 29 days. Energy-related options (Figure 6b), those which efforts have been focused on historically, provide over $60 \%$ of the resource-use improvements (4.4\% of total exergy input). In parallel, material-related options yield the remaining $2.8 \%$ available (Figure 6c).

Figure $6 \mathrm{~b}$ reveals that the recovery of BOSG yields the largest improvement in utilisation: 


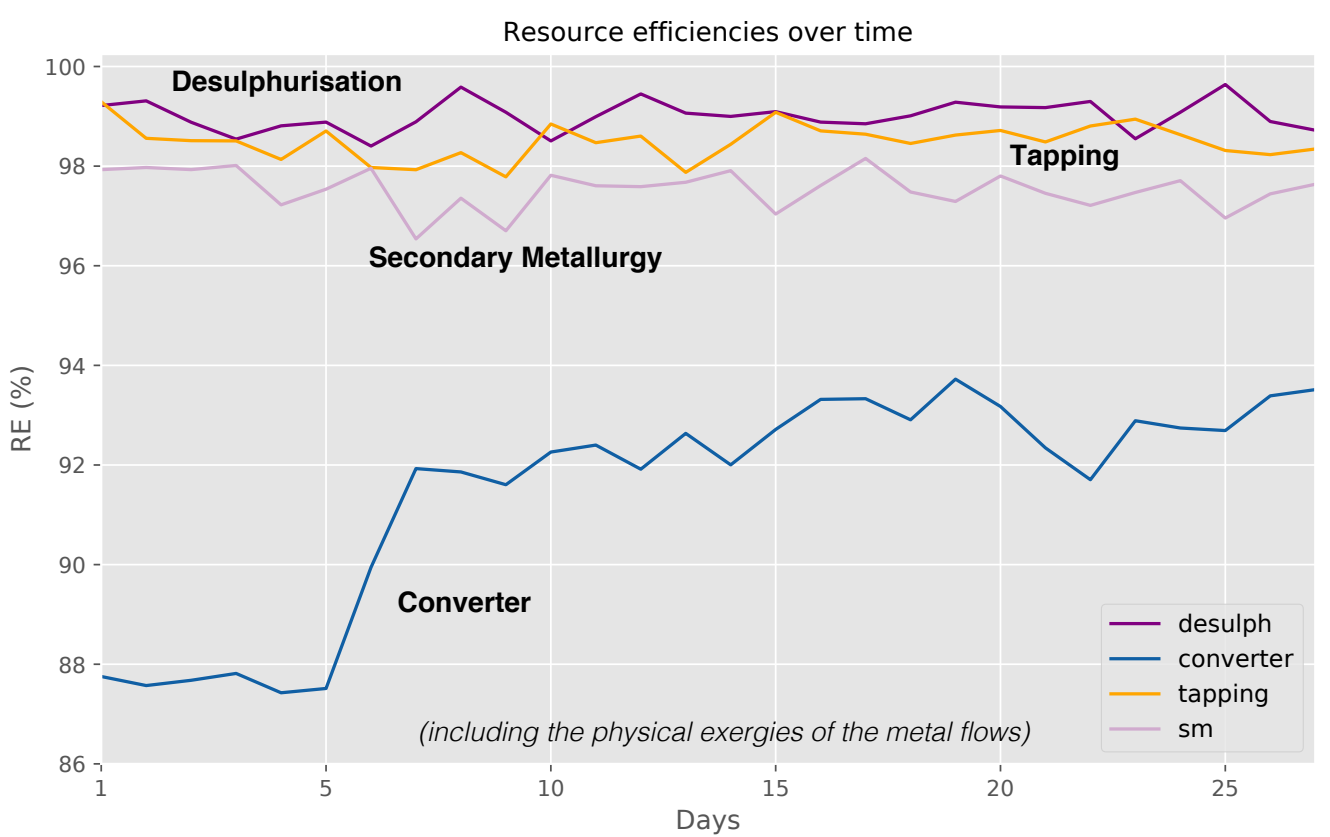

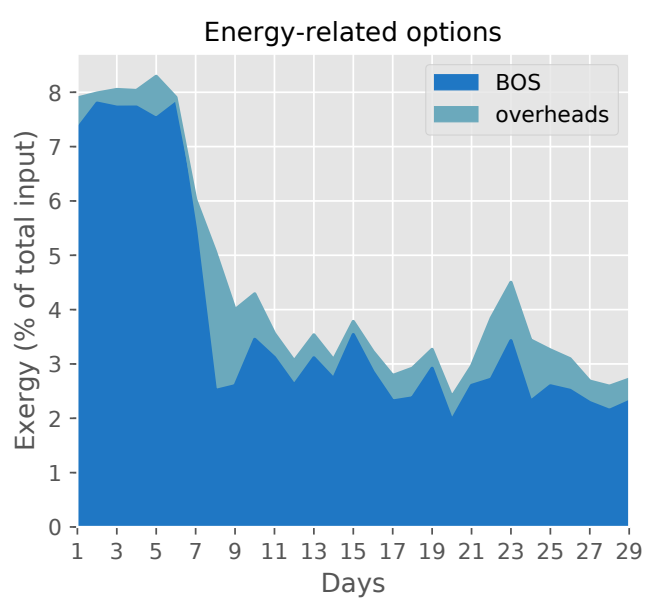

(b)

(a)

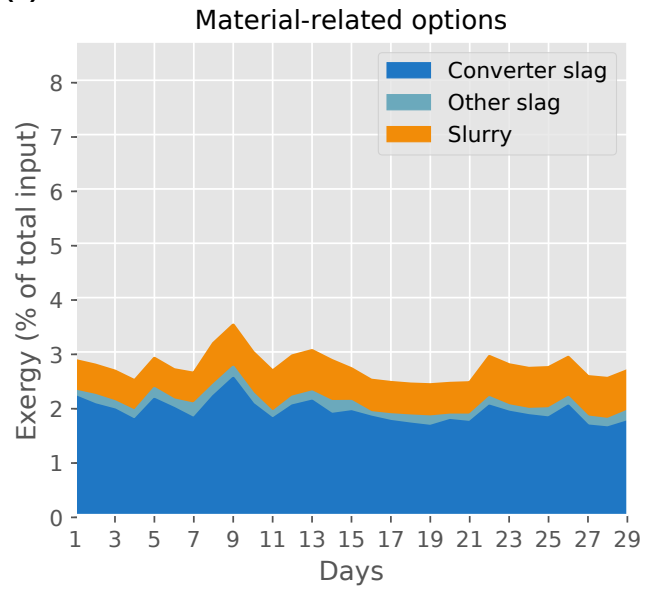

(c)

Figure 6: (a): RE variation across time; (b): improvements from EE options; (c): improvements from ME options.

up to about $8 \%$ of the total daily exergy input. This potential, which is the most variable ranging from $1 \%$ to $8 \%$ of the daily exergy use - is greatest in the first week during which most of the BOSG was wasted ( 7-8\%). For Days 1 to 7 , in which part of the BOSG is recovered, the energy and material efficiency options are comparable in size (about $2.7 \%$ of the daily exergy input). The amount of BOSG that can be recovered is primarily limited by two aspects: the recovery infrastructure, i.e. gas holders and site-wide piping; and the variations in the energy demand of the processes in which this would be further consumed.

Reducing the amount of overheads per tonne of steel on a daily basis results in savings equivalent to $0.2-2.6 \%$ of the total inputs (with an absolute STD of $0.5 \%$ ). As the overheads are mainly used for the preheating of ladles, the amount of overheads consumed is likely to be affected by the process durations and the waiting times in between these.

From within the ME options in Figure 6c, the recovery of converter slag provides the largest 
improvement in resource utilisation, equivalent to about 1.6-2.5\% of the daily exergy inputs (0.2\% STD). This steelmaking slag is commonly used internally within sinter plants. Further re-using the tapping and secondary slag provide 0.1-0.2\% for further use (with a STD of less than $0.1 \%$ ). Currently, the BOS slags have two main applications: as road aggregates, and to produce Portland cement. As explained in a report by the US office of Energy Efficiency and Renewable Energy [60], its use in the latter application can be limited by high concentrations of $\mathrm{MgO}$ and $\mathrm{FeO}$. Other applications include anti-skid material for icy roads.

Recovering the converter slurry, resulting from the cleaning of the BOSG, provides about $0.6-0.8 \%$ for further use (with a STD of less than $0.1 \%$ ). This by-product is often fed into on-site sinter plants. However, difficulties in recovering slurry arise due to its high Zinc content, which if recirculated round, can contaminate the steel.

\subsection{Resource efficiency versus energy intensity}

To demonstrate the added value of measuring resource efficiency in units of exergy, this is compared to conventional energy intensity (EI) metrics. Based on Equation 2.10 in Section 2.3.4, Equation 3.1 shows the converter's normalised energy intensity $\left(E I_{\text {norm }}\right)$. $E$ is energy, $M$ is mass, and prod and by-prod are the main product and by-products. This is portrayed in Figure 7a for the 29 day period.

$$
E I_{\text {norm }}=\left(\frac{E_{\text {inputs }}-E_{\text {by-prod }}}{M_{\text {prod }}}\right) E I_{\text {max }}^{-1}=\left(\frac{E_{\text {gas }}+E_{\text {elec }}-E_{\text {steam }}-E_{\mathrm{BOSG}}}{M_{\text {steel }}}\right) E I_{\text {max }}^{-1}
$$

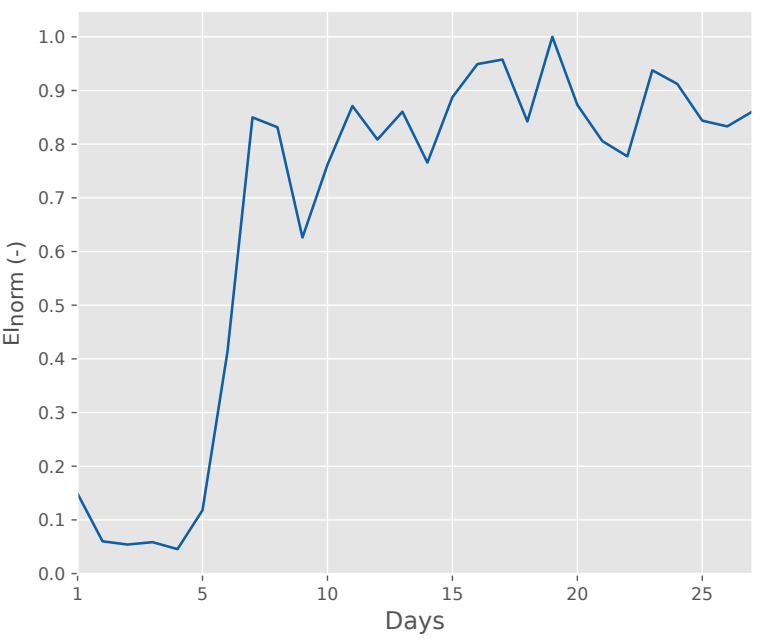

(a)

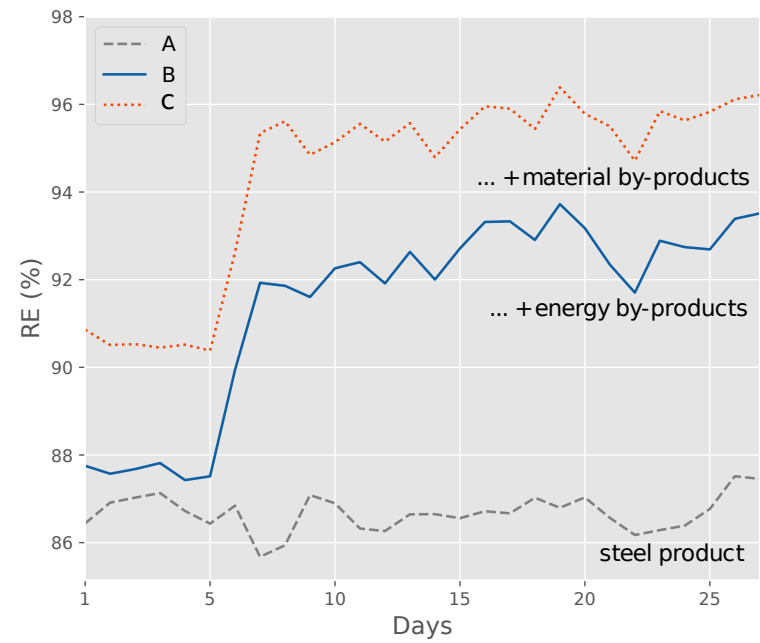

(b)

Figure 7: (a) Energy intensity ( $\left.E I_{\text {norm }}\right)$ across the 29 days for the converter; for confidentiality reasons EI is normalised to its absolute maximum value (1.0 is the lowest). (b) the converter's RE, where (A) considers the steel output as the only useful output, (B) includes the recovery of energy by-products and (C) includes material by-products.

Figure 7b shows the converter's resource efficiency, outlined in Equation 3.2 and based on Equation 2.9 in Section 2.3.4. Equation 3.2 - where $H M$ is hot metal, and the superscript mat 
stands for materials - shows the overall expression for RE, where the appropriate elements for each RE definition are denoted with (B) and (C) superscripts. In Figure 7b, the RE is disaggregated into three parts: (A) where the steel is the only useful product; (B) where recovered energy by-products (e.g. BOSG and steam) are included; (C) where material by-products (i.e. slag and slurry) are also assumed to be recovered. RE (B), portrayed in blue in Figure 7b matches the RE definition from Section 2.3.4 and Figures 5 and 6.

$R E=\frac{B_{\text {prod }}^{M}+\left(B^{E}+B^{M}\right)_{\text {by-prod }}}{\left(B^{E}+B^{M}\right)_{\text {inputs }}}=\frac{B_{c h+p h}^{\text {steel }}+B_{c h}^{\text {BOSG (B) }}+B_{p h}^{\text {steam (B) }}+B_{c h}^{\text {slag (C) }}+B_{c h}^{\text {slurry (C) }}}{B_{c h}^{\text {gas }}+B_{c h}^{\text {elec }}+B_{c h+p h}^{\mathrm{HM}}+B_{c h}^{\text {fluxes }}+B_{c h}^{\text {scrap }}}$

Figures $7 \mathrm{a}$ and $7 \mathrm{~b}$ show that the expressions for the $E I_{\text {norm }}(7 \mathrm{a})$ and $\mathrm{RE}(7 \mathrm{~b})$ exhibit a similar trend when the energy by-products currently recovered (B) are included in the numerator. However, unlike the energy intensity, the resource efficiency captures the converter's raw material input variability, the heterogeneity in chemical composition (through the chemical exergy) and can additionally reveal improvements in the amount of both energy and material by-products recovered (version $\mathrm{C}$ ). In contrast, the $E I_{\text {norm }}$ metric can only be modified to credit improvements in the recovery of energy by-products (Equation 3.1), overlooking opportunities to make material-related improvements (the gap between $\mathrm{RE}(\mathrm{B})$ and $\mathrm{RE}(\mathrm{C})$ ).

The use of an exergy-based RE changes the traditional definition of best performer, and places options such as reducing raw material inputs and recovering material by-products on the same level-playing field as energy-related ones. Additionally, this RE metric is dimensionless and can therefore be used to compare processes more widely across different industries.

\section{Discussion}

This study uses energy and material data from the control system of a BOS plant to analyse the resource use and efficiency of its processes during real operations - practice that is currently not implemented at the plant. For the first time, energy and materials were jointly visualised and measured under a single framework: exergy. Resource use for individual batches and days were monitored using Sankey diagrams (measured in units of exergy) over a period of 29 days; this helped enhance the understanding of resource flows within the plant and facilitated communication with decision-makers at high management levels.

The analysis reveals that:

- An integrated and transparent picture of the BOS plant's internal resource flows can be constructed using available energy and material control data. This, however, requires cleaning the data and matching up inconsistent spatial and temporal scales.

- Heterogeneity in the RE is observed across batches in a day and across days in a month (Section 3.1). Based on this, there is still potential to improve resource use through both 
energy- and material-related options (Section 3.2). The sum of potential improvements in resource use amounts to $7 \%$ of the total exergy input during the 29 days.

- For the last three weeks, the fraction of resource use improvements arising from material efficiency strategies is about $40 \%$. This highlights the importance of tracking the use of materials alongside that of direct process energy.

Previous studies analysing the exergy efficiency of BOS plants have revealed potential improvement options and given firms a means to compare their own performance. Costa et al. (2001) [32] estimate that recovering all by-products and wastes could increase the plant's RE from 75 to $85 \%$. More recently, in an analysis of a steelmaking network, Wu et al. (2016) [29] report an exergy efficiency of $95.8 \%$ - the steam, BOSG, sludge, dust, and slag produced are all fully recovered. Although comparing aggregated resource efficiencies on a yearly basis can provide plants with guidance on potential interventions, this provides limited insight into the operational details behind these measures. Other studies using more disaggregated plant-level data, however, either investigate simulations/models, e.g. [12,61], or if using control data, are limited to the analysis of specific technologies $[20,62]$; neither of these provide an integrated picture of the system's overall operational performance.

In practice, encouraging the implementation of energy and material efficiency in industry requires a more detailed and holistic awareness of real resource use variations - e.g. batches or days - over entire systems. This study provides this, and in so doing improves conventional approaches used by industry practitioners to analyse resource efficiency in five ways.

1. Using control data creates a resource picture that is more representative of current operations than simulations or other top-down analyses. This is beneficial because it helps plant operators make real decisions about potential solutions, and because an improved physical balance facilitates a more accurate accounting of resources.

2. This study provides the prerequisites to better understand what variables influence RE. Capturing the effects of these variables gives plant managers insight into changes available during operation. Automatically using control data is also an effective alternative to reduce the time, cost and expertise required in traditional energy audits.

3. Currently, material efficiency strategies, such as improving yields or recovering material by-products, are pursued to reduce costs and not recognised as energy-saving interventions. By incorporating materials into the resource efficiency metric, it is possible to capture and therefore incentivise ME measures alongside those on energy efficiency (Section 3.3). Our integrated approach has a direct impact on industry's interpretation of a "best performer" and gives plant managers an alternative, more holistic metric which they can benchmark daily performance to.

4. Visualising the flows of materials and energy in a single diagram improves the visibility of the plant's resource flows, and facilitates comparisons between energy and materialrelated improvement options, as well as the communication of information to higher 
management systems (Section 3.1).

5. This study provides a decision-support tool that can bridge the gap between high-level indicators, which give little steer about how to improve processes, and extensive chemical engineering models, which are costly to run and time-consuming.

The long-term objective of this work is to develop and implement a decision-support software tool that can provide any industry firm with a detailed and holistic understanding of its resource efficiency, and to do so by directly obtaining data from its control system. The research presented in this paper is the backbone of such tool.

Before this can be fully implemented in industry, however, it must be further automated, and integrated into plants' hardware structures and decision-making practices. More case studies of different industrial processes will also be needed to expand the applicability of this approach to other industry sectors, specifically to improve the adaptability of: (1) the exergy method; (2) the data filtering process; (3) and the construction of the balancing model.

Alongside these necessary developments, five future research avenues were identified from extensive discussions with plant managers and control operators. These include:

- expanding the scope of improvement measures to include, for example, the increase of scrap-to-hot metal input ratio, the decrease idle and processing times; and reductions in iron and steel yield losses;

- expanding system boundaries - larger material efficiency improvements arise by including downstream rolling processes and upstream sintering and iron-making processes;

- quantifying result uncertainties to account for temporal and spatial misalignments in the data - some batches still have small negative imbalances (i.e. in the input);

- standardising the method to other sectors;

- understanding whether and how much batch-to-batch variations can be reduced.

\section{Conclusions}

This study presents the first attempt at using available control data to conduct an integrated exergy analysis of energy and materials at the operational scales of batches and days. This was exemplified through the study of a basic oxygen steelmaking plant during a period of 29 days and covering 900 batches. The value residing in control data was exploited by automatically constructing Sankey diagrams that depict the resource use of the plant across individual batches and days; these improved the plant's visibility of the size and structure of its internal resource flows.

Based on these constructed flows, resource efficiency improvements from increasing the utilisation of energy and material by-products, and reducing the overheads consumed were 
computed. In total, over $7 \%$ of the total exergy input to the plant over this period could be avoided. Most promising is the fact that about $40 \%$ of these direct savings arise from reductions in material use - the remaining $60 \%$ results from improvements in energy use. Energy savings available from reducing material use would have been missed if a conventional energy study that which is currently common practice in this plant - had been performed.

This novel approach has proved valuable for incentivising material efficiency as a way of reducing energy use and therefore for enabling more holistic and better-informed decisions on resource efficiency measures at actionable scales in industry. The automated, holistic and transparent nature of this method could prove to be an effective alternative to reduce the time, cost and expertise required in traditional energy audits. As part of a wider collaboration between industry and academia, this research is the fundamental proof-of-concept from which a decision-support software will be developed.

\section{Acknowledgements}

This research is funded by Emerson Electric co. This study was supported by Tata Steel UK. We thank the team at Port Talbot, specially Chris Williams and Chris Barnes, who provided insight and expertise that assisted the research.

\section{A Appendix}

This appendix provides additional information relevant to two sections of this paper: the method described in Section 2; and the results summarised in Section 3.

\section{A.1 Additional information for the method}

The decisions made during the filtering of the raw data are summarised in Table A.1.

Individual resources flows are combined into groups if these are invisible on the diagrams. The groupings change depending on the scope analysed. Table A.2 summarises the groupings used in different visuals throughout this study.

\section{A.2 Additional considerations for the results}

Figure A.1 depicts the batch-level variations in RE for the entire BOS plant. 
Table A.1: Process of filtering out wrong/conflicting data inputs

\begin{tabular}{|c|c|c|c|}
\hline Data type & Missing data & Check & Filled in with \\
\hline \multirow[t]{4}{*}{ Composition } & Slag & \multirow{4}{*}{$\begin{array}{l}\text { Are batch-level compositions } \\
\text { available? }\end{array}$} & \multirow{4}{*}{$\begin{array}{l}\text { Yes: take previous composition; } \\
\text { No: take average composition from } \\
\text { average }\end{array}$} \\
\hline & Slurry & & \\
\hline & Scrap & & \\
\hline & Hot metal & & \\
\hline \multirow[t]{3}{*}{ Mass } & Tap weights & \multirow{2}{*}{$\begin{array}{l}\text { Was the previous/following } \\
\text { batch logged? }\end{array}$} & $\begin{array}{l}\text { Yes: take value for previous batch; } \\
\text { No: take average value }\end{array}$ \\
\hline & Slag weights & & $\begin{array}{l}\text { Yes: take value for previous batch; } \\
\text { No: take average slag-to-tap weight } \\
\text { ratio }\end{array}$ \\
\hline & Hot metal weights & $\begin{array}{l}\text { For converter: check that oxy- } \\
\text { gen was input }\end{array}$ & $\begin{array}{l}\text { Yes: take value for previous batch; } \\
\text { No: discard batch }\end{array}$ \\
\hline $\begin{array}{l}\text { Physical } \\
\text { properties }\end{array}$ & Temp./press. & Check previous batches & Yes: take previous; No: take average \\
\hline \multirow[t]{2}{*}{ Identifiers } & Batch numbers & $\begin{array}{l}\text { Check previous and following } \\
\text { batches in heat log }\end{array}$ & $\begin{array}{l}\text { If error remains unclear, remove batch } \\
\text { from dataset }\end{array}$ \\
\hline & Time-stamps & $\begin{array}{l}\text { For converter: use oxygen } \\
\text { data; For rest: check log for } \\
\text { other processes; or whether } \\
\text { inputs were recorded }\end{array}$ & $\begin{array}{l}\text { For converter - Yes: take average; } \\
\text { No: remove batch; For rest - Yes: if } \\
\text { tapping, remove batch; if desulph or } \\
\text { sm, use average. No: remove batch }\end{array}$ \\
\hline
\end{tabular}

Table A.2: Sankey diagram groupings

\begin{tabular}{lll}
\hline Level & Group name & Materials included \\
\hline \multirow{3}{*}{ Batch } & Slag & Converter, DS, tapping and secondary slag \\
& Slurry & Sludge and grit \\
& Scrap & Eight types of scrap inputs \\
\hline \multirow{4}{*}{ Daily } & Overheads & Electricity, COG, NG \\
& Fluxes & Lime, magnesium, dolomite, ore \\
& Additions & Ferro-alloys, carbon, silicon manganese \\
& Nitrogen & Nitrogen 6 bar and 16 bar \\
\hline
\end{tabular}

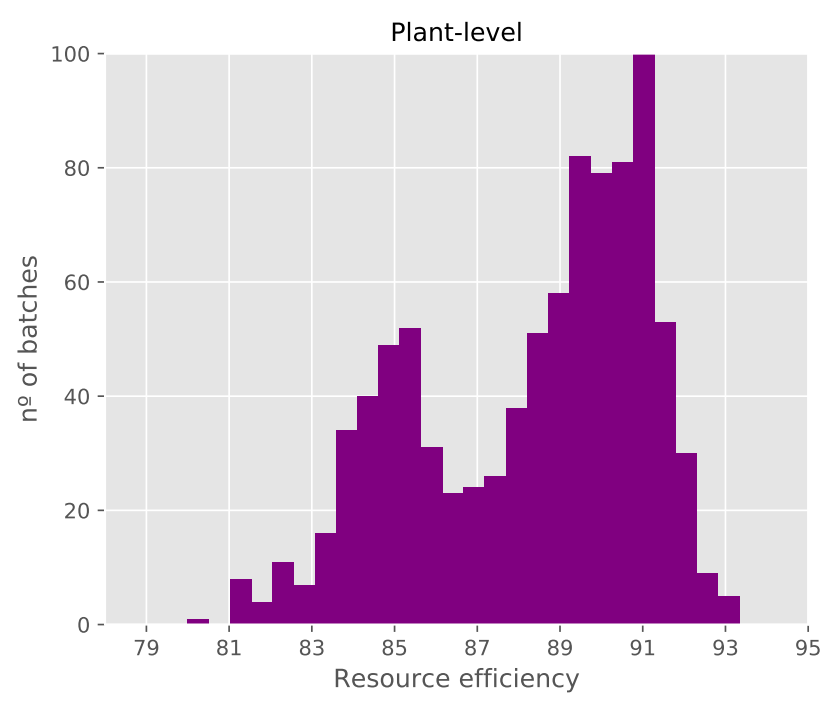

Figure A.1: Resource flow diagram for a given batch (measured in mass) 


\section{References}

[1] J. M. Allwood, M. F. Ashby, T. G. Gutowski, and E. Worrell, "Material efficiency: A white paper," Resources, Conservation and Recycling, vol. 55, no. 3, pp. 362-381, 2011. [Online]. Available: http://dx.doi.org/10.1016/j.resconrec.2010.11.002

[2] J. M. Cullen, J. M. Allwood, and M. D. Bambach, "Mapping the Global Flow of Steel: From Steelmaking to End-Use Goods," Environmental Science \& Technology, vol. 46, pp. 13048-13 055, 2012.

[3] J. M. Cullen and J. M. Allwood, "Mapping the Global Flow of Aluminum: From Liquid Aluminum to End-Use Goods," Environmental Science \& Technology, vol. 47, pp. 3057-3064, 2013.

[4] E. Worrell, A. P. C. Faaij, G. J. M. Phylipsen, and K. Blok, "An approach for analysing the potential for material efficiency improvement," Resources, Conservation and Recycling, vol. 13, no. 3-4, pp. 215-232, 1995.

[5] IEA, "World Energy Outlook," 2015.

[6] R. L. Milford, J. M. Allwood, and J. M. Cullen, "Assessing the potential of yield improvements, through process scrap reduction, for energy and $\mathrm{CO} 2$ abatement in the steel and aluminium sectors," Resources, Conservation and Recycling, vol. 55, no. 12, pp. 1185-1195, oct 2011.

[7] D. R. Cooper, A. C. H. Skelton, M. C. Moynihan, and J. M. Allwood, "Component level strategies for exploiting the lifespan of steel in products," Resources, Conservation and Recycling, vol. 84, pp. 24-34, 2014.

[8] A. C. Serrenho, Z. S. Mourão, J. Norman, J. M. Cullen, and J. M. Allwood, "The influence of UK emissions reduction targets on the emissions of the global steel industry," Resources, Conservation and Recycling, vol. 107, pp. 174-184, 2016.

[9] S. Pauliuk, R. L. Milford, D. B. Müller, and J. M. Allwood, "The Steel Scrap Age," Environmental Science \& Technology, vol. 47, no. 7, pp. 3448-3454, 2013.

[10] Q. Zhang, J. Xu, Y. Wang, A. Hasanbeigi, W. Zhang, H. Lu, and M. Arens, "Comprehensive assessment of energy conservation and CO2 emissions mitigation in China's iron and steel industry based on dynamic material flows," Applied Energy, vol. 209, pp. 251-265, 2018.

[11] I. Matino, V. Colla, and S. Baragiola, "Quantification of energy and environmental impacts in uncommon electric steelmaking scenarios to improve process sustainability," Applied Energy, vol. 207, pp. 543-552, 2017.

[12] N. Karali, W. Y. Park, and M. McNeil, "Modeling technological change and its impact on energy savings in the U.S. iron and steel sector," Applied Energy, vol. 202, pp. 447-458, 2017.

[13] S. Alvandi, G. Bienert, W. Li, and S. Kara, "Hierarchical Modelling of Complex Material and Energy Flow in Manufacturing Systems," Procedia CIRP, vol. 29, pp. 92-97, 2015. [Online]. Available: http://linkinghub.elsevier.com/retrieve/pii/S2212827115000256

[14] E. Abele, N. Panten, and B. Menz, "Data Collection for Energy Monitoring Purposes and Energy Control of Production Machines," Procedia CIRP, vol. 29, pp. 299-304, 2015. [Online]. Available: http://dx.doi.org/10.1016/j.procir.2015.01.035

[15] P. Ghadimi, W. Li, S. Kara, and C. Herrmann, "Integrated Material and Energy Flow Analysis towards Energy Efficient Manufacturing," Procedia CIRP, vol. 15, pp. 117-122, 2014. [Online]. Available: http://linkinghub.elsevier.com/retrieve/pii/S2212827114004338

[16] N. Denz, L. Ausberg, M. Bruns, and T. Viere, "Supporting resource efficiency in chemical industries IT-based integration of flow sheet simulation and material flow analysis," Procedia CIRP, vol. 15, no. 3, pp. 537-542, 2014. [Online]. Available: http://dx.doi.org/10.1016/j.procir.2014.06.060

[17] T. Viere, L. Ausberg, M. Bruns, J. Eschke, J. Hedemann, H. Lambrecht, M. Schmidt, T. Schröer, F. Schulenburg, B. Schwartze, M. Stockmann, K. Witt, and E. Zschieschang, "Integrated Resource Efficiency Analysis for Reducing Climate Impacts in the Chemical Industry," Journal of Business Chemistry, 2014. 
[18] E. Zschieschang, N. Denz, H. Lambrecht, and T. Viere, "Resource efficiency-oriented optimization of material flow networks in chemical process engineering," Procedia CIRP, vol. 15, pp. 373-378, 2014. [Online]. Available: http://dx.doi.org/10.1016/j.procir.2014.06.066

[19] P. Eberspächer, P. Schraml, J. Schlechtendahl, A. Verl, and E. Abele, "A Model- and Signal-based Power Consumption Monitoring Concept for Energetic Optimization of Machine Tools," Procedia CIRP, vol. 15, pp. 44-49, 2014. [Online]. Available: http://linkinghub.elsevier.com/retrieve/pii/S2212827114004430

[20] G. F. Porzio, B. Fornai, A. Amato, N. Matarese, M. Vannucci, L. Chiappelli, and V. Colla, "Reducing the energy consumption and $\mathrm{CO} 2$ emissions of energy intensive industries through decision support systems An example of application to the steel industry," Applied Energy, vol. 112, pp. 818-833, 2013.

[21] K. Kellens, W. Dewulf, M. Overcash, M. Z. Hauschild, and J. R. Duflou, "Methodology for systematic analysis and improvement of manufacturing unit process life-cycle inventory (UPLCI)CO2PE! initiative (cooperative effort on process emissions in manufacturing). Part 1: Methodology description," The International Journal of Life Cycle Assessment, vol. 17, pp. 69-78, 2012. [Online]. Available: http://link.springer.com/10.1007/s11367-011-0340-4

[22] S. Thiede, Energy efficiency in manufacturing systems, C. Herrmann and S. Kara, Eds. Springer, 2012.

[23] C. Herrmann and S. Thiede, "Process chain simulation to foster energy efficiency in manufacturing," CIRP Journal of Manufacturing Science and Technology, vol. 1, no. 4, pp. 221-229, jan 2009. [Online]. Available: http://linkinghub.elsevier.com/retrieve/pii/S1755581709000121

[24] V. Wohlgemuth, B. Page, and W. Kreutzer, "Combining Discrete Event Simulation and Material Flow Analysis based on a Component-Oriented Approach to Industrial Environmental Protection," University of Canterbury, Tech. Rep., 2007.

[25] T. G. Gutowski, M. S. Branham, J. B. Dahmus, A. J. Jones, A. Thiriez, and D. P. Sekulic, "Thermodynamic Analysis of Resources Used in Manufacturing Processes," Environmental Science \& Technology, vol. 43, no. 5, pp. 1584-1590, mar 2009. [Online]. Available: http://pubs.acs.org/doi/abs/10.1021/es8016655

[26] N. Eisenmenger, B. Warr, and A. Magerl, "Trends in Austrian Resource Efficiency: An Exergy and Useful Work Analysis in Comparison to Material Use, CO2 Emissions, and Land Use," Journal of Industrial Ecology, vol. 21, no. 5, pp. 1250-1261, 2017.

[27] F. Bühler, T.-v. Nguyen, and B. Elmegaard, "Energy and exergy analyses of the Danish industry sector," vol. 184, pp. 1447-1459, 2016.

[28] D. Flórez-Orrego and S. de Oliveira Junior, "On the efficiency, exergy costs and CO2 emission cost allocation for an integrated syngas and ammonia production plant," Energy, vol. 117, pp. 341-360, 2016.

[29] J. Wu, R. Wang, G. Pu, and H. Qi, "Integrated assessment of exergy, energy and carbon dioxide emissions in an iron and steel industrial network," Applied Energy, vol. 183, pp. 430-444, 2016. [Online]. Available: http://dx.doi.org/10.1016/j.apenergy.2016.08.192

[30] S. H. Khattak, "An exergy based method for resource accounting in factories," Doctor of Philosophy, De Montfort University, Leicester, 2016.

[31] M. Fröhling, F. Schwaderer, H. Bartusch, and F. Schultmann, "A Material Flow-based Approach to Enhance Resource Efficiency in Production and Recycling Networks," Journal of Industrial Ecology, vol. 17, no. 1, pp. 5-19, feb 2013. [Online]. Available: http://dx.doi.org/10.1111/j.1530-9290.2012.00502.x

[32] M. M. Costa, R. Schaeffer, and E. Worrell, "Exergy accounting of energy and materials flows in steel production systems," Energy, vol. 26, no. 4, pp. 363-384, 2001.

[33] R. U. Ayres and L. W. Ayres, Accounting for resources, 2: The life-cycle of materials. Edward Elgar Publishing Limited, 1999.

[34] J. de Beer, E. Worrell, and K. Blok, "Future technologies for energy-efficient iron and steel making," Annual review Energy Environment, no. 23, pp. 123-205, 1998.

[35] N. Nakicenovic, P. V. Gilli, and R. Kurz, "Regional and global exergy and energy efficiencies," Energy, vol. 21, no. 3, pp. 223-237, 1996. 
[36] G. Bisio, "Exergy method for efficient energy resource use in the steel industry," Energy, vol. 18, no. 9, pp. 971-985, 1993.

[37] G. Wall, "Exergy flows in industrial processes," Energy, vol. 13, pp. 197-208, 1988.

[38] worldsteel, Yield Improvement in the Steel Industry: working group report 2003-2006, 2009.

[39] T. Gao, L. Shen, M. Shen, L. Liu, and F. Chen, "Analysis of material flow and consumption in cement production process," Journal of Cleaner Production, vol. 112, pp. 553-565, 2016.

[40] R. L. Milford, S. Pauliuk, J. M. Allwood, and D. B. Müller, "The Roles of Energy and Material Efficiency in Meeting Steel Industry CO2 Targets," Environmental Science \& Technology, vol. 47, no. 7, pp. 3455-3462, apr 2013.

[41] V. Brodyansky, M. Sorin, P. Le Goff, and P. Pilavachi, The efficiency of industrial processes: exergy analysis and optimization. Elsevier, 1994.

[42] J. Szargut, D. R. Morris, and F. R. Steward, Exergy Analysis of Thermal, Chemical, Es Metallurgical Processes. New York: Hemisphere Publishing Corporation, 1988.

[43] R. U. Ayres, L. W. Ayres, and A. Masini, "An application of exergy accounting to five basic metal industries," Sustainable Metals Management, pp. 141-194, 1996.

[44] M. Schmidt, "The Sankey Diagram in Energy and Material Flow Management," Journal of Industrial Ecology, vol. 12, no. 2, pp. 173-185, apr 2008. [Online]. Available: http: //doi.wiley.com/10.1111/j.1530-9290.2008.00015.x

[45] K. Soundararajan, H. K. Ho, and B. Su, "Sankey diagram framework for energy and exergy flows," Applied Energy, vol. 136, pp. 1035-1042, 2014. [Online]. Available: http: //dx.doi.org/10.1016/j.apenergy.2014.08.070

[46] European Commission, Synthesis of the stakeholder consultation Delivering more Sustainable Consumption and Production, 2012. [Online]. Available: http://ec.europa.eu/environment/archives/eussd/pdf/ results $\left\{{ }_{-}\right\}$consultation.pdf

[47] J. Szargut, Exergy Method: Technical and Ecological Applications. WIT Press, 2005.

[48] M. Reuter, U. Boin, v. S. A, E. Verhoef, K. Heiskanen, Y. Yang, and G. Georgalli, "Thermodynamics of recycling metallurgy," in The Metrics of Material and Metal Ecology: Harmonizing the Resource, Technology and Environmental Cycles. Elsevier, 2005.

[49] J. Szargut, "Standard chemical exergy of some elements and compounds on the planet Earth," Energy, vol. 11, no. 8, pp. 733-755, 1986.

[50] J. Szargut and Egzergia, "Appendix 1. Standard chemical exergy," Tech. Rep., 2007.

[51] J. J. G. Romera, "IAPWS (The International Association for the Properties of Water and Steam)," 2016. [Online]. Available: http://www.iapws.org/release.html

[52] E. Querol, B. Gonzalez-Regueral, and J. L. Perez-Benedito, Practical approach to exergy and thermoeconomic analysis of industrial processes. Springer, 2013.

[53] I. Dincer and M. A. Rosen, Exergy: energy, environment and sustainable development. Elsevier, 2007.

[54] J. Dewulf, H. Van Langenhove, B. Muys, S. Bruers, B. R. Bakshi, G. F. Grubb, D. M. Paulus, and E. Sciubba, "Exergy: Its Potential and Limitations in Environmental Science and Technology," Environmental Science \& Technology, vol. 42, no. 7, pp. 2221-2232, apr 2008.

[55] R. Lupton and J. Allwood, "Hybrid Sankey diagrams: visual analysis of multidimensional data for understanding resource use," Resources, Conservation and Recycling, vol. 124, pp. 141-151, 2017.

[56] R. C. Lupton, "ricklupton/sankeyview: v1.1.7. zenodo." December 2017. [Online]. Available: http://doi.org/10.5281/zenodo.1098904

[57] J. D. Hunter, "Matplotlib: A 2d graphics environment," Computing In Science E Engineering, vol. 9, no. 3, pp. 90-95, 2007. 
[58] World Steel Association, "Fact sheet: steel industry by-products," Tech. Rep., 2016.

[59] B. R. Bakshi, T. G. Gutowski, and D. P. Sekulic, Thermodynamics and the destruction of resources. Cambridge University Press, 2011.

[60] Office of US energy efficiency and renewable energy, "Steel Industry Technology Roadmap," Tech. Rep., 2001.

[61] C. Wang, M. Brämming, and M. Larsson, "Numerical model of scrap blending in BOF with simultaneous consideration of steel quality, production cost, and energy use," pp. 387-394, 2013. [Online]. Available: https://www.scopus.com/inward/record.uri?eid=2-s2.0-84875877120\{\&\}doi=10. $1002\{\%\} 2$ Fsrin.201200185 $\{\&\}$ partnerID=40\{\&\}md5=44871e1f79a01a7d5aa97aaccc3a0af4

[62] H. Zhou, F. Zhang, D. Zhang, and L. Zhang, "Study on BOF gas dedusting technology at contemporary steel plant," pp. 1422-1425, 2013. [Online]. Available: https://www.scopus.com/inward/record.uri?eid=2-s2.0-84871891763\{\&\}doi=10.4028\{\%\}2Fwww. scientific.net $\{\%\} 2$ FAMR.610-613.1422 $\{\&\}$ partnerID=40 $\{\&\}$ md5=d6c5b3eaaf96a521846f1096bbeef295 


\section{Supplementary Material: additional method information}

Accompanying the research article titled: 'Control data, Sankey diagrams, and exergy: assessing the resource efficiency of industrial plants' Author: Ana Gonzalez Hernandez

This supplementary material provides additional information regarding the material and energy flow analysis (MEFA) described in Section 2.3 of the main article. Tables A.3, A.4 and A.5 outline, in more detail, the assumptions made and calculations performed for each individual resource stream in the BOS plant. The resource streams are described according to their 'source', 'target', and 'material'. The tables are divided into the four relevant processes - desulphurisation, converter vessel, tapping, and secondary metallurgy (SM) and an explanation is provided for the mass (in tonnes) and the exergy (in gigajoules) analyses. 


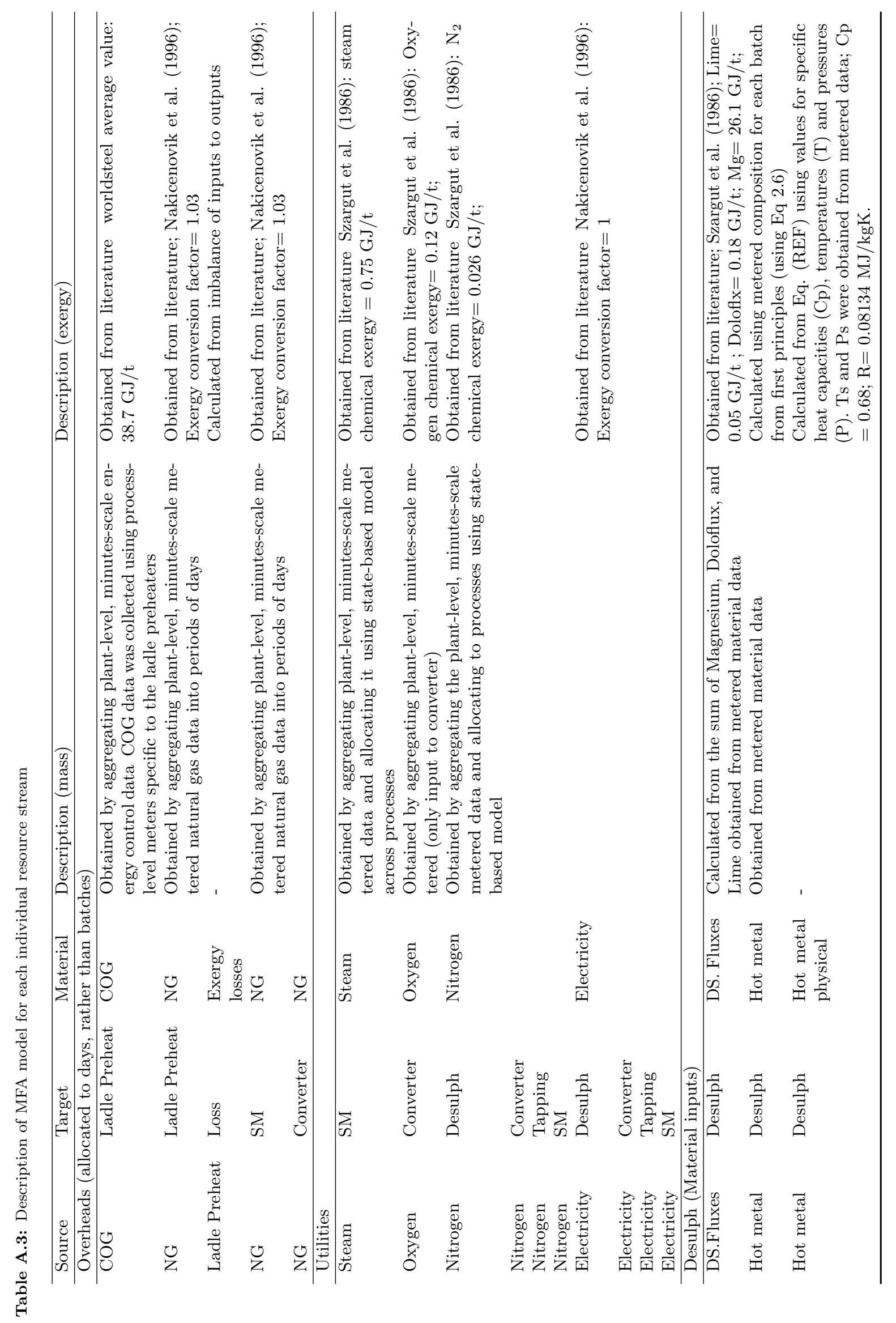




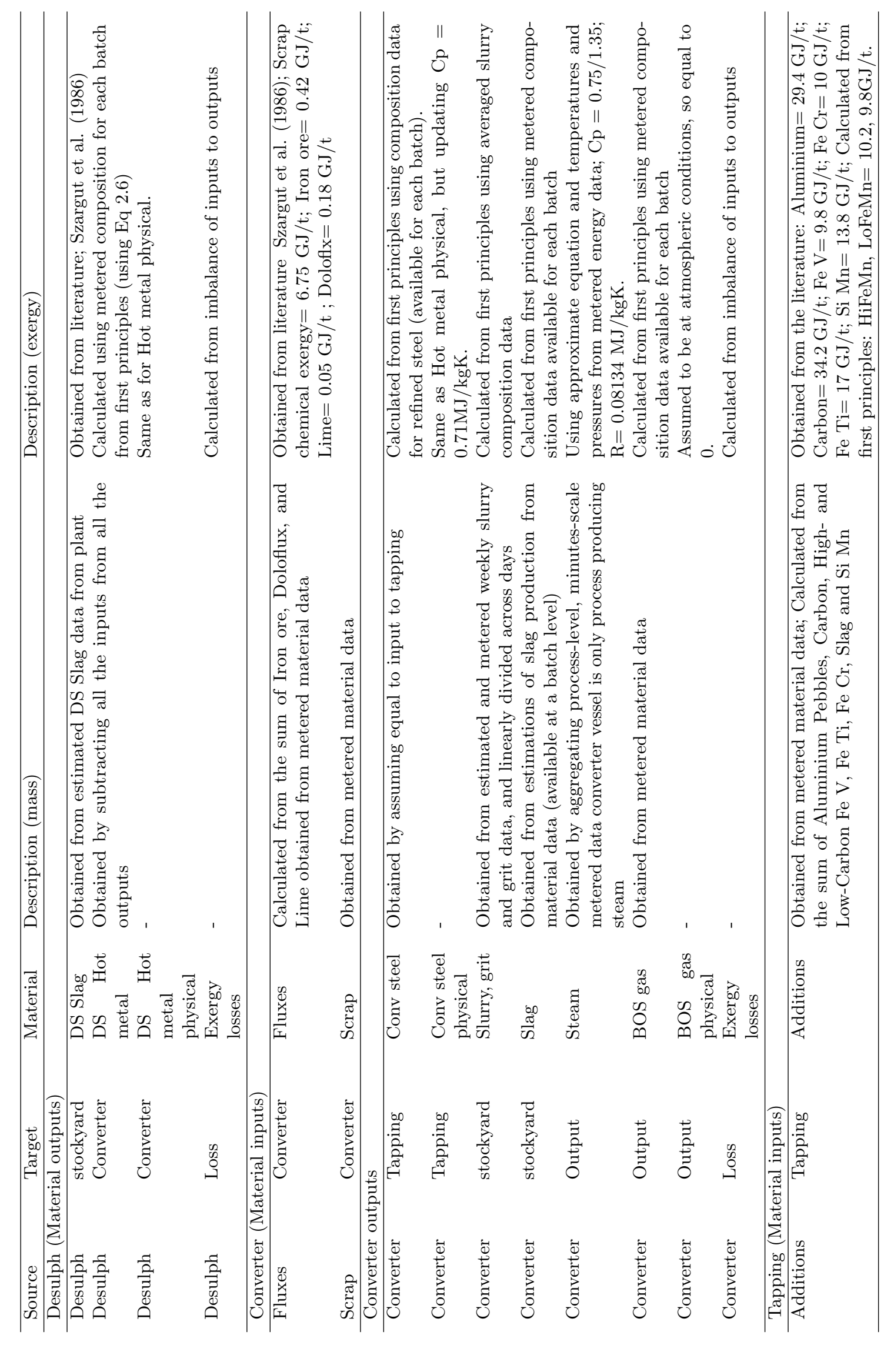




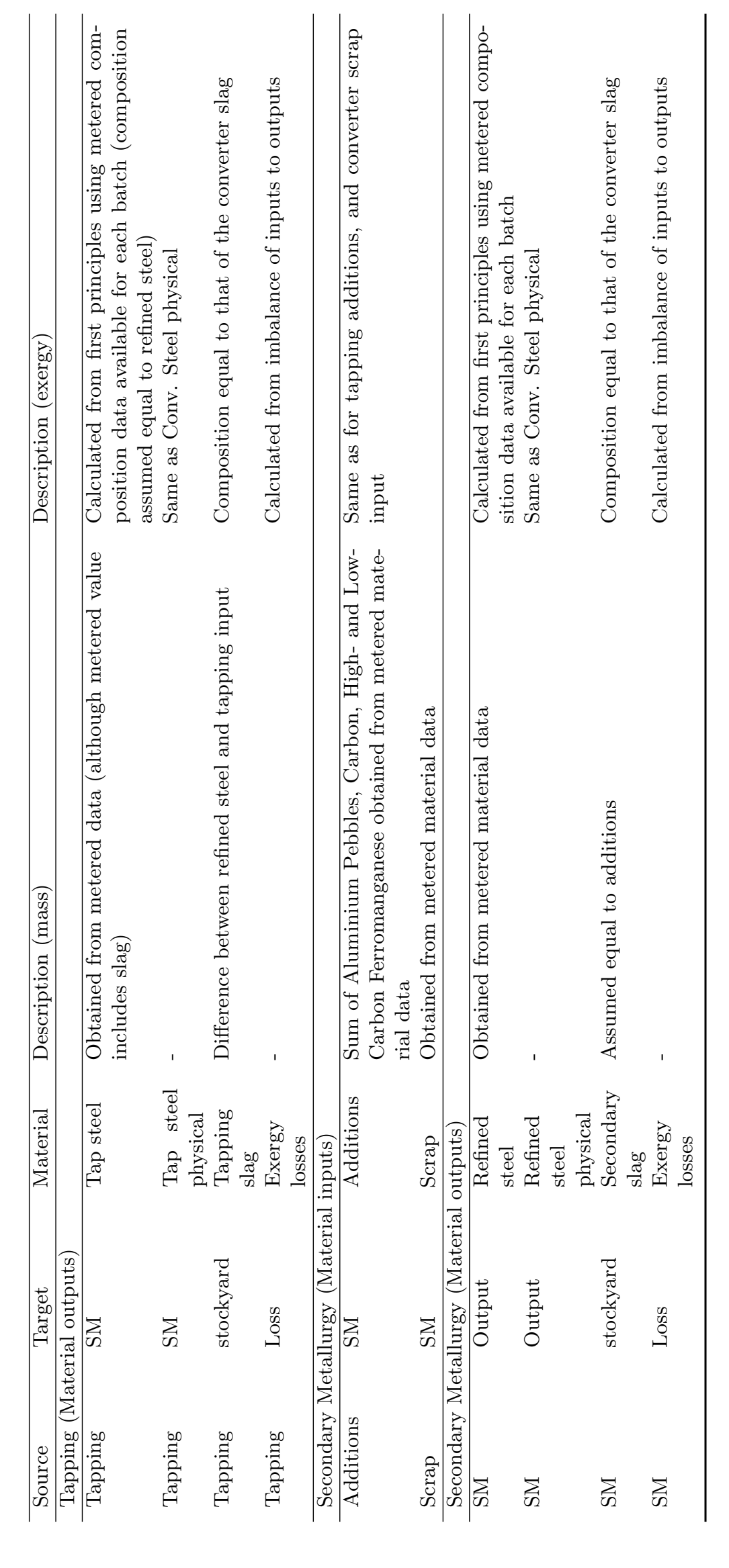

